\title{
Associação de níveis séricos de vitamina D3 e doenças orais - Revisão Sistemática
}

\author{
Association of serum vitamin D3 levels and oral diseases - Systematic Review \\ Asociación de niveles séricos de vitamina D3 y enfermedades bucales - Revisión Sistemática
}

Stephane Silva Santana

ORCID: https://orcid.org/0000-0002-3061-6661

Centro Universitário de Patos de Minas, Brasil

E-mail: stephanesantana@unipam.edu.br

Ivânia Aparecida Pimenta Santos Silva

ORCID: https://orcid.org/0000-0001-7012-8497

Centro Universitário de Patos de Minas, Brasil E-mail: ivaniapimenta@unipam.edu.br

Gustavo Augusto Santos

ORCID: https://orcid.org/0000-0001-8113-7516 Universidade Federal de Minas Gerais, Brasil E-mail: guaugustto@yahoo.com.br

Adriano Luís Pulquério de Almeida ORCID: https://orcid.org/0000-0002-6166-8229 Centro Universitário de Patos de Minas, Brasil E-mail: adrianoalmeida@unipam.edu.br Rodrigo Soares de Andrade ORCID: https://orcid.org/0000-0001-6114-0929 Centro Universitário de Patos de Minas, Brasil E-mail: rodrigosa@unipam.edu.br

\begin{abstract}
Resumo
O metabólito ativo da vitamina D3, o colecalciferol, é um hormônio multifuncional, que atua na regulação da homeostase do cálcio e do fósforo e que além disso, vem mostrado resultados promissores como imunomodulador, agente antitumoral entre outras funções. Destarde, essa revisão sistemática objetiva revisar na literatura científica como o colecalciferol atua como modulador hormonal e qual é seu papel frente a patologias orais. Foi realizada uma busca nas bases de dados PubMed (MEDLINE), Scopus, Embase, Google Scholar e The Cochrane Library, tendo como critérios de inclusão estudos os quais recorrerão assuntos referente à saúde oral associada ao uso do colecalciferol. Encontramos várias patologias orais que fazem associação com o colecalciferol, e verificamos seu papel na inflamação, na quimioprevenção e como um agente antitumoral, revelamos também que níveis baixos dessa vitamina estão associados ao aparecimento e /ou predisposição de patologias orais. Concluímos que a manutenção de níveis séricos ideais de colecalciferol é muito importante para a preservação e manutenção saúde bucal assim como para a saúde sistêmica.
\end{abstract}

Palavras-chave: Colecalciferol; Vitamina D3; Doenças bucais.

\begin{abstract}
The active metabolite of vitamin D3, cholecalciferol, is a multifunctional hormone that acts in the regulation of calcium and phosphorus homeostasis and which, in addition, has shown promising results as an immunomodulator, an antitumor agent, among other functions. Therefore, this systematic review aims to review in the scientific literature how cholecalciferol acts as a hormonal modulator and what is its role in oral pathologies. A search was carried out in the PubMed (MEDLINE), Scopus, Embase, Google Scholar and The Cochrane Library databases, having as inclusion criteria studies which will use issues related to oral health associated with the use of cholecalciferol. We found several oral pathologies that are associated with cholecalciferol, and we verified its role in inflammation, chemoprevention and as an antitumor agent, we also revealed that low levels of this vitamin are associated with the appearance and/or predisposition of oral pathologies. We conclude that maintaining optimal serum cholecalciferol levels is very important for the preservation and maintenance of oral health as well as systemic health.
\end{abstract}

Keywords: Colecalciferol; Vitamin D3; Mouth diseases.

\section{Resumen}

El metabolito activo de la vitamina D3, colecalciferol, es una hormona multifuncional que actúa en la regulación de la homeostasis del calcio y fósforo y que, además, ha mostrado resultados prometedores como inmunomodulador, agente antitumoral, entre otras funciones. Por tanto, esta revisión sistemática tiene como objetivo revisar en la literatura científica cómo actúa el colecalciferol como modulador hormonal y cuál es su papel en las patologías bucales. Se 
realizó una búsqueda en las bases de datos PubMed (MEDLINE), Scopus, Embase, Google Scholar y The Cochrane Library, teniendo como criterios de inclusión estudios que utilizarán temas relacionados con la salud bucal asociados al uso de colecalciferol. Encontramos varias patologías bucales que se asocian con colecalciferol, y verificamos su papel en la inflamación, quimioprevención y como agente antitumoral, también revelamos que niveles bajos de esta vitamina se asocian con la aparición y / o predisposición de patologías bucales. Concluimos que mantener niveles óptimos de colecalciferol sérico es muy importante para la preservación y mantenimiento de la salud bucal, así como la salud sistémica.

Palabras clave: Colecalciferol; Vitamina D3; Enfermedades de la boca.

\section{Introdução}

A vitamina D é um hormônio multifuncional e atua principalmente na regulação do equilíbrio do cálcio e do fósforo sendo, portanto, esse seu efeito chamado de "clássico" porém, essa vitamina também está envolvida nos processos metabólicos do tecido ósseo e dos dentes, assim como também exibe propriedades imunomoduladoras importantes (Bashutski et al., 2011; Kühnisch et al., 2015; Schroth et al., 2016). Ela possui duas formas principais, a vitamina D3 ou colecalciferol (25[OH]D), que é formado na pele após a exposição à luz solar ou ultravioleta, e a vitamina D2 ou ergocalciferol, que é obtida através dos alimentos (Kühnisch et al., 2015).

Quanto a saúde bucal, o nível inadequado de colecalciferol pode estar relacionado a uma ampla variedade de distúrbios (Hiremath, 2013; Uwitonze et al., 2018). Quando em níveis séricos corretos seus benefícios vão além dos efeitos na (re)mineralização dos dentes, mas também atuam nas funções anti-inflamatórias e da capacidade de estimular a produção de peptídeos antimicrobianos (Hiremath, 2013; Penoni, 2016).

Os níveis séricos considerados seguros estão entre 100 a 160 nmol/1 (nano molar por litro), visto que pessoas que moram em países próximos a linha do equador e, portanto, tem uma exposição maior ao sol tendem a ter níveis de colecalciferol mais altos (Hildebolt, 2005). Níveis menores que $80 \mathrm{nmol} / \mathrm{l}$ são considerados deficientes por demonstrarem que há redução da absorção de cálcio e aumento da secreção de paratormônio (PTH) ( Hiremath, 2013).

A ingestão de 600 a 800 UI por dia de colecalciferol é recomenda pela Food and Nutrition Board (FNB) do Instituto de Medicina dos Estados Unidos da América (EUA) (Sainaghi et al., 2013). Quanto à intoxicação por essa vitamina, não há relatos de intoxicação após exposição solar, apesar de que a intoxicação possa causar hipercalcemia; nesses casos, os níveis séricos de colecalciferol foram acima de $200 \mathrm{nmol} / 1$ ( Hiremath, 2013).

A carência dessa vitamina tem mostrado comprometimento na odontogênese e também foi associado a doença periodontal, podendo estar envolvido no mecanismo imunológico dessa doença (Schroth et al., 2016). Quando em níveis adequados, o colecalciferol tem mostrado potencial na prevenção do câncer, de infecções, bem como em distúrbios do cálcio e dos ossos (Kühnisch et al., 2015).

A preservação dos níveis séricos adequados de colecalciferol mostra estar associada a melhores condições de saúde oral, porém a implicação da suplementação para deficiência de colecalciferol exige mais evidências para permitir conclusões (Aerden, 2018; Kühnisch et al., 2015). Assim, este estudo tem como objetivo principal revisar na literatura como o colecalciferol atua como modulador hormonal e qual é seu papel frente a patologias orais.

\section{Metodologia}

Essa revisão sistemática foi desenvolvida de acordo com as recomendações do PRISMA (Liberati et al., 2009).

Estratégia de busca: Utilizando as bases de dados PubMed (MEDLINE), Scopus, Embase, Google Scholar e The Cochrane Library foram utilizados os seguintes descritores em língua inglesa "vitamin D AND oral pathologies "cholecalciferol mouth disease" "25-hydroxyvitamin D3 oral health" "vitamin D3 AND oral autoimmune diseases"; restringindo a pesquisa para o idioma inglês. 
Critérios de inclusão e exclusão: Os artigos alcançados através da busca nas bases de dados foram avaliados e definidos como compatíveis ou não com o objetivo. Foram incluídos estudos os quais recorreram assuntos referente à saúde oral associada ao uso do colecalciferol e foram excluídos os artigos aos quais não foi possível obter o acesso, revisões de literatura e artigos que fujam do tema, que não se refiram a patologias orais.

Seleção de estudo: Estudos de coorte prospectivos ou retrospectivos, série de casos e relatos de casos com descrição clínica e / ou laboratorial. Os títulos e resumos de todos os relatórios nas pesquisas eletrônicas foram cada um lido por dois investigadores separadamente. Os estudos que cumprirão os critérios de inclusão e aqueles que não apresentarem informações suficientes em o título ou no resumo, foram avaliados na íntegra.

Extração de dados: Os dados do estudo foram extraídos independentemente por meio de formulários de extração específicos usando o software Microsoft Excel. Para o estudo selecionado, as seguintes informações foram extraídas (quando disponíveis): autor e ano de publicação, tipo de artigo, patologia abordada no artigo, objetivo do estudo, dosagem de colecalciferol e resultados.

Análise: Todas as informações foram avaliadas para cruzamento de dados.

\section{Resultados}

As pesquisas nas bases de dados resultaram em 196 artigos encontrados e que foram selecionados com base nos seus títulos e resumos sendo que, 43 destes foram excluídos por serem duplicatas. 65 artigos foram excluídos com base nos critérios de exclusão. Dos estudos excluídos, 22 eram revisões de literatura, 14 deles não foi possível obter acesso ao texto completo e 29 foram excluídos após leitura completa por fugirem ao objetivo do trabalho, resultando então em 88 artigos que atendem aos critérios (Figura 1). Com base nesses 88 artigos, realizamos a revisão por meio da leitura integra dos mesmo e seus principais dados foram destacados na tabela abaixo (Tabela 1).

Encontramos várias patologias orais que fazem associação com o colecalciferol, e verificamos seu papel na inflamação, na quimioprevenção e como um agente antitumoral, revelamos também que níveis baixos dessa vitamina estão associados ao aparecimento e /ou predisposição de patologias orais. 
Research, Society and Development, v. 10, n. 15, e481101523019, 2021

(CC BY 4.0) | ISSN 2525-3409 | DOI: http://dx.doi.org/10.33448/rsd-v10i15.23019

Figura 1: Fluxograma do processo de busca na literatura.
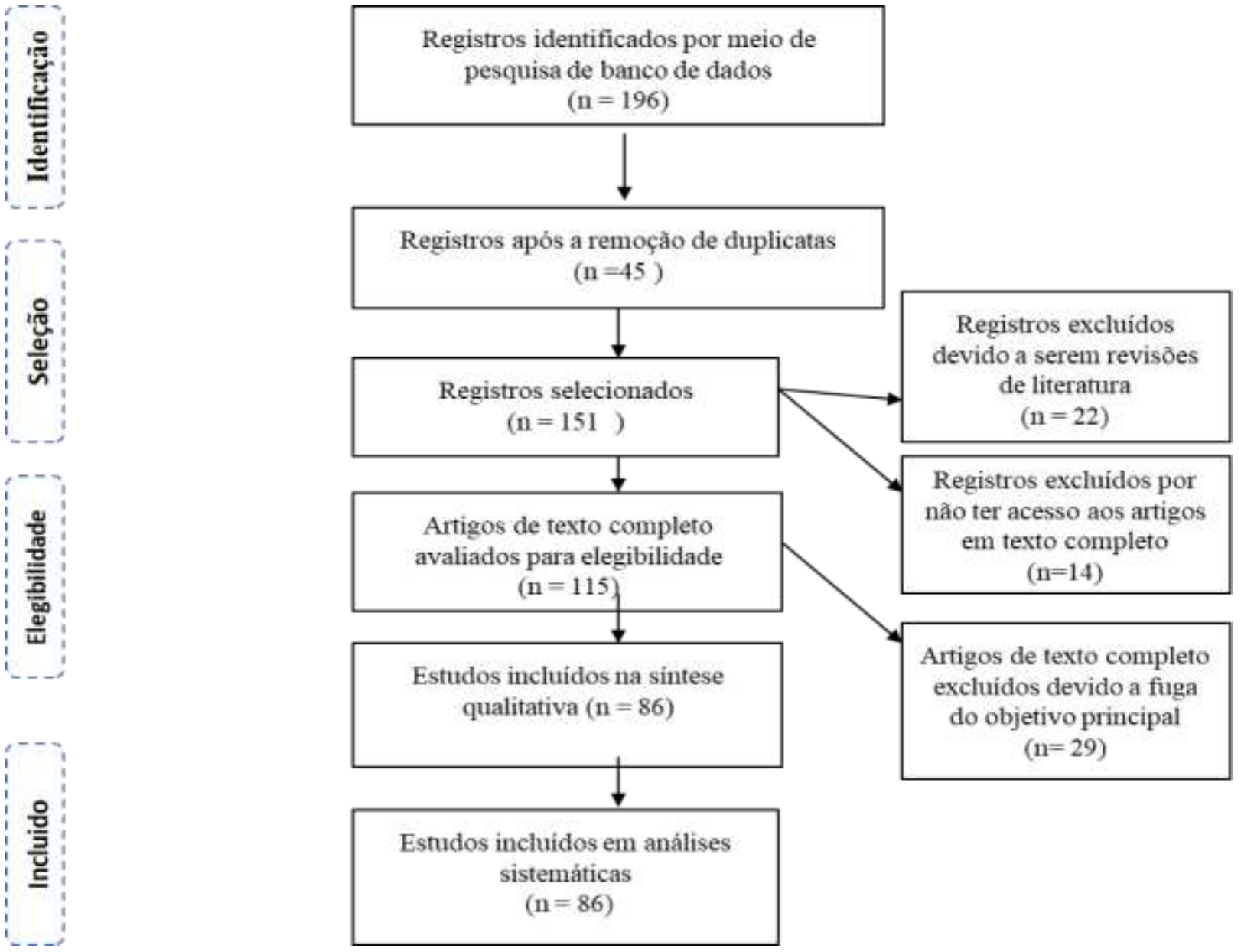

Fonte: Autores. 
Research, Society and Development, v. 10, n. 15, e481101523019, 2021

(CC BY 4.0) | ISSN 2525-3409 | DOI: http://dx.doi.org/10.33448/rsd-v10i15.23019

Tabela 1 - Artigos incluídos na análise sistemática mostrando as patologias encontradas, dose e resultados encontrados pelos autores.

\begin{tabular}{|c|c|c|c|c|c|}
\hline $\begin{array}{l}\text { Autor e ano } \\
\text { de } \\
\text { publicação } \\
\end{array}$ & $\begin{array}{l}\text { Tipo do } \\
\text { artigo }\end{array}$ & Objetivos & Condição & Dosagem & Resultado \\
\hline $\begin{array}{l}\text { FERGUSON, } \\
\text { H. W.; } \\
\text { HARTLES, } \\
\text { R. L. } 1964 \text {. }\end{array}$ & $\begin{array}{c}\text { Caso- } \\
\text { controle }\end{array}$ & $\begin{array}{l}\text { Investigar as mudanças que ocorrem na formação da } \\
\text { dentina incisiva e do osso alveolar em animais privados } \\
\text { de cálcio ou fósforo na presença e ausência de vitamina } \\
\text { D }\end{array}$ & $\begin{array}{c}\text { Formação de } \\
\text { dentina }\end{array}$ & N/A & $\begin{array}{l}\text { Quando o conteúdo dietético de cálcio e fósforo é adequado, as } \\
\text { necessidades de vitamina D do rato são muito baixas. No entanto, os } \\
\text { pequenos desvios do normal que foram ocasionalmente observados } \\
\text { sublinharam a necessidade de um estudo mais aprofundado. }\end{array}$ \\
\hline $\begin{array}{l}\text { HARTLES, } \\
\text { R. L.; } \\
\text { SHAPIRO, I. } \\
\text { M. } 1966 .\end{array}$ & $\begin{array}{l}\text { Estudo } \\
\text { experime } \\
\text { ntal }\end{array}$ & $\begin{array}{l}\text { Investigar as mudanças no padrão de mineralização no } \\
\text { dente incisivo de ratos decorrentes de deficiências } \\
\text { dietéticas extremas de cálcio ou fósforo e determinar o } \\
\text { efeito da vitamina D sobre essas mudanças. }\end{array}$ & Mineralização & N/A & $\begin{array}{l}\text { A adição de vitamina } \mathrm{D} \text { à dieta com baixo teor de fósforo causou } \\
\text { menos melhora do que no caso da dieta com baixo teor de cálcio. }\end{array}$ \\
\hline $\begin{array}{l}\text { BENDER, I. } \\
\text { B.; } \\
\text { NAIDORF, } \\
\text { Irving J. } 1985\end{array}$ & $\begin{array}{l}\text { Relato de } \\
\text { caso }\end{array}$ & $\begin{array}{l}\text { Apresentar observações deste sinal patognomônico em } \\
12 \text { casos e } 38 \text { outros casos reunidos na literatura nos } \\
\text { quais o sinal radiográfico específico esteve presente às } \\
\text { vezes, mas não foi enfatizado. Além disso, desejamos } \\
\text { oferecer uma hipótese de por que a patose periapical } \\
\text { nesta doença não responde favoravelmente ao } \\
\text { tratamento endodôntico. }\end{array}$ & $\begin{array}{l}\text { Lesão periapical em } \\
\text { pessoas com } \\
\text { raquitismo } \\
\text { resistente a vitamina } \\
\text { D }\end{array}$ & N/A & \\
\hline $\begin{array}{l}\text { BERDAL, } \\
\text { Ariane et al. } \\
1987 \text {. }\end{array}$ & & $\begin{array}{l}\text { Foi estudado o papel da vitamina } \\
\text { desenvolvimento do germe dentário. }\end{array}$ & $\begin{array}{l}\text { Desenvolvimento } \\
\text { dentário. }\end{array}$ & N/A & $\begin{array}{l}\text { A vitamina D tem um papel nos eventos iniciais do dente } \\
\text { desenvolvimento: } \text { morfogênese, histodiferenciação e } \\
\text { citodiferenciação de células pulpares, bem como no esmalte e } \\
\text { mineralização da dentina. }\end{array}$ \\
\hline $\begin{array}{l}\text { ABE, Keiko } \\
\text { et al. } 1988 .\end{array}$ & & $\begin{array}{l}\text { Examinar histopatologicamente o defeito dos dentes } \\
\text { decíduos em pacientes com raquitismo hipofosfatemico } \\
\text { resistente a vitamina D e explicar a diferença na } \\
\text { gravidade das manifestações dentárias. }\end{array}$ & $\begin{array}{l}\text { Deformidade } \\
\text { estrutural de dentes } \\
\text { decíduos de } \\
\text { pacientes com } \\
\text { raquitismo } \\
\text { resistente a vitamina } \\
\text { D. }\end{array}$ & N/A & N/A \\
\hline $\begin{array}{l}\text { ABE, K. et al. } \\
1989 .\end{array}$ & & $\begin{array}{l}\text { Comparar a cristalinidade dos dentes decíduos em } \\
\text { raquitismo resistente a vitamina D com a dos dentes de } \\
\text { crianças saudáveis. }\end{array}$ & $\begin{array}{l}\text { Raquitismos } \\
\text { resistente a vitamina } \\
\text { D. }\end{array}$ & N/A & $\begin{array}{l}\text { A cristalinidade da dentina do dente decíduo em raquitismo } \\
\text { resistente a vitamina } \mathrm{D} \text { foi maior do que a da dentina normal, } \\
\text { principalmente por causa dos grandes cristais de hidroxiapatita na } \\
\text { dentina globular de raquitismo resistente a vitamina D. }\end{array}$ \\
\hline $\begin{array}{l}\text { MULLER, K. } \\
\text { et al. } 1990\end{array}$ & & $\begin{array}{l}\text { Investigar se o metabolismo da vitamina D3 perturbado } \\
\text { acompanha a síndrome de Sjogren primária, } \\
\text { examinando as concentrações sanguíneas de vitamina } \\
\text { D3 e fenótipos de globulina Gc, a principal proteína de } \\
\text { ligação da vitamina D3 no sangue. }\end{array}$ & $\begin{array}{l}\text { Sindrome de } \\
\text { sjogren }\end{array}$ & N/A & $\begin{array}{l}\text { Encontraram concentrações sanguíneas severamente diminuídas de } \\
\text { 25-OHD3 em pacientes com síndrome de Sjogren primária. Não está } \\
\text { claro se o metabolismo alterado da vitamina D3 está relacionado à } \\
\text { imunopatologia desta doença ou é apenas um epifenômeno }\end{array}$ \\
\hline
\end{tabular}


Research, Society and Development, v. 10, n. 15, e481101523019, 2021

GEDLICKA,

Claudia et al.

2006

Encontrar outros inibidores responsáveis pela inibição do crescimento em uma linha celular sem regulação positiva de $\mathrm{p} 21$.

CHAUSSAIN

-MILLER, C.

et al. 2007.

Avaliar o resultado do tratamento com $1(\mathrm{OH})$ vitamina $\mathrm{D}$ e fosfato oral na estrutura da dentina em pacientes com raquitismo hipofosfatêmico familiar e expressão de SIBLINGs (uma família de proteínas não colágenas envolvidas na dentinogênese) e osteocalcina.

DO, Jeong

Eun et al.

2008.

Associação entre a expressão de receptores Toll-Like e a concentração sérica de vitamina $\mathrm{D}$ em doença de Beçet.

LIU, Kaining Estudo Avaliou se existe uma associação entre as et al. 2009 coorte concentrações plasmáticas de calcifediol e periodontite agressiva e se os níveis plasmáticos de biomarcadores ósseos (osteocalcina, fosfatase alcalina, cálcio e fósforo) regulados pela vitamina $\mathrm{D}$ estão relacionados a periodontite agressiva.

DESCROIX, Discriminar entre os papéis específicos de $1 \alpha 25(\mathrm{OH}) 2$

V. et al. 2010

vitamina D 3, calcemia / fosfatemia e o material ambiente final em mutantes nulos de VDR de camundongo.

HOKUGO,

Akishige et al.

2010.

LIU, Kaining

et al. 2010

Estabelecer um modelo animal de osteonecrose da mandíbula relacionado com bisfosfonatos, testando a combinação desses fatores de risco.

Investigou a influência da terapia periodontal inicial nos níveis sistêmicos e locais de 25 hidroxivitamina D3 e três elementos relacionados (osteocalcina e interleucina-1b e -6) em pacientes com periodontite agressiva generalizada.

SPOLIDORI Estudo Investigou os efeitos do tratamento intermitente com

$\mathrm{O}$, Luís C. et experime 1,25 vitamina D e calcitonina na perda óssea alveolar

al. $2010 . \quad$ ntal

induzida por perda óssea associada a ciclosporina em ratos.

$\begin{array}{lll}\text { BASHUTSKI } & \text { Ensaio } & \text { Avaliou os resultados da cirurgia periodontal e da } \\ \text {, J. D. et al. } & \text { clínico } & \text { administração de teriparatida em indivíduos suficientes }\end{array}$

longitu
Carcinoma

espinocelular de

cabeça e pescoço

Estrutura da dentina

no raquitismo

hipofosfatemico

familiar.

N/A

ença de beçet

N/A

Periodontite

N/A

Dentes

N/A

Osteonecrose

N/A

Periodontite

N/A

Perda óssea

alveolar.

N/A

Periodontite

800 UI de

vitamina D
Ilustra a coexistência de diferentes vias da ação da vitamina D na

diferenciação dentária e biomineralização.

Indica que 1,25 (OH) 2 Vitamina D 3 medeia sua inibição de crescimento por meio de dois importantes CDK inibidores em linhagens de células de câncer de cabeça e pescoço.

O tratamento de crianças hipofosfatêmicas com 1- $(\mathrm{OH})$ vitamina D e fosfato oral garante um bom desenvolvimento e mineralização da dentina e evita anomalias clínicas, como a necrose dentária classicamente associada à doença. $O$ início do tratamento na primeira infância e a boa adesão à terapia são imprescindíveis para observar esses efeitos benéficos.

Resultados sugerem que a inflamação desencadeada por TLR2 e TLR4 é importante na patogênese da doença de Beçet. E isso parece possível que a vitamina D possa ser usada como uma opção terapêutica modulando a expressão de monócitos de TLR2 e TLR4 na doença de Beçet.

Os níveis plasmáticos de calcifediol podem estar associados à inflamação periodontal.

É sugerido que o (s) mecanismo (s) fisiopatológico (s) que sustentam a Osteonecrose da mandíbula podem envolver a interação entre bifosfonatos e funções comprometidas da vitamina D no domínio da homeostase esquelética e imunidade inata.

Os níveis de 25-hidroxivitamina D3 e interleucina-1b foram sistemicamente e localmente reduzidos em pacientes com GAgP pela terapia periodontal inicial. 25-hidroxivitamina D3 pode estar envolvida na inflamação periodontal

A terapia intermitente com calcitriol / calcitonina previne a perda óssea alveolar induzida por perda óssea alveolar induzida por ciclosporina em ratos e normaliza a produção de mediadores inflamatórios associados.

A deficiência de vitamina D no momento da cirurgia periodontal afeta negativamente os resultados do tratamento por até 1 ano. A análise desses dados sugere que o nível de vitamina $\mathrm{D}$ pode ser crítico para a cura pós-cirúrgica. 
Research, Society and Development, v. 10, n. 15, e481101523019, 2021

(CC BY 4.0) | ISSN 2525-3409 | DOI: http://dx.doi.org/10.33448/rsd-v10i15.23019
FINK,
Relato de
caso
Disgeusia
$2000 \mathrm{UI} / \mathrm{dia}$
Michael. 2011

JABBAR, S.

et al. 2011

Investigou a relação entre doença periodontal, citocinas plasmáticas, vitamina D e densidade mineral óssea em mulheres na pós-menopausa com e sem osteoporose.

JAGUR, Estudo Comparou as alterações radiográficas na articulação Oksana et al. transversa temporomandibular (ATM) com a densidade minera 2011. 1 óssea da coluna lombar e colo do fêmur. Encontrar se há alguma relação entre as alterações radiográficas da ATM, vitamina D $(25(\mathrm{OH}) \mathrm{D})$ e níveis de marcadores ósseos e o número de dentes perdidos.

Relato de Relatar o tratamendo endodôntico em paciente com raquitismo resistente a vitamina $\mathrm{D}$.

ZACHOU,

Evanthia.

2012.

DALIRSANI,

Zohreh et al.

Ensaio

clinico Avaliou os efeitos da combinação de 5-fluorouracil,
ácido 13-cis retinóico e vitamina D 3 em células cultivadas de carcinoma espinocelular oral.

MAŁODOBR

A-MAZUR,

Estudo

Avaliar a influência de dois polimorfismo de

Małgorzata et

onal

nucleotídeo único no gene VDR (rs2238135 e

rs2107301) no desenvolvimento do câncer.

al. 2012

AGHA-

HOSSEINI,

Farzaneh;

MIRZAII-

DIZGAH,

Iraj;

MIRJALILI,

Nargess.

2013

HIREMATH, Estudo Avaliar o efeito anti-inflamatório da vitamina D na

Vishwanath P. clínico

et al. 2013

Estudo Comparar saliva total não estimulada 25-

caso-

hidroxicolecalciferol $(25(\mathrm{OH})$ D) em mulheres na

controle. menopausa com e sem sensação de boca seca e avaliar

a relação entre saliva $25(\mathrm{OH})$ D e gravidade de

Sensação de boca seca. randomiz

$\begin{array}{cc}\text { Doença Periodontal } & \text { N/A } \\ \begin{array}{c}\text { ATM e perca } \\ \text { dentária }\end{array} & \text { N/A }\end{array}$

Tratamento

endodontico

Carcinoma

espinocelular oral

N/A

Carcinoma Oral

Xerostomia

N/A

A

O diagnóstico precoce, o tratamento convencional e o exame radiográfico contínuo são fatores importantes na melhora das alterações dentárias em pacientes com raquitismo resistente a vitamina D.

Como a combinação de drogas teve mais efeito inibitório sobre a proliferação celular do que uma delas e a combinação de três drogas teve o efeito mais apoptótico do que uma dessas drogas separadamente, essas drogas podem ter efeito sinérgico no Carcinoma espinocelular oral

Fornece evidências de uma associação genética entre rs2238135 no gene VDR e a ocorrência e risco de câncer de cavidade oral.

O nível de concentração salivar de $25(\mathrm{OH}) \mathrm{D}$ pode ser maior em mulheres na menopausa com sensação de boca seca do que no grupo de controle, e há uma correlação positiva entre a gravidade da sensação de boca seca e saliva total não estimulada $25(\mathrm{OH}) \mathrm{D}$.

Existe um efeito antiinflamatório dose-dependente da vitamina D sobre a gengivite. A vitamina D é um agente antiinflamatório seguro e eficaz em doses que variam de 500 UI a 2.000 UI. Os resultados ado, são aparentes mais cedo com a dose mais alta de 2.000 UI 
Research, Society and Development, v. 10, n. 15, e481101523019, 2021

\begin{tabular}{|c|c|c|c|c|c|}
\hline & $\begin{array}{l}\text { duplo- } \\
\text { cego, } \\
\text { controlad } \\
\text { o por } \\
\text { placebo }\end{array}$ & & & & \\
\hline $\begin{array}{l}\text { LI, Hao et } \\
\text { al. } 2013 \text {. }\end{array}$ & $\begin{array}{l}\text { Estudo } \\
\text { experime } \\
\text { ntal }\end{array}$ & $\begin{array}{l}\text { Preparação de um tratamento de liberação sustentada de } \\
\text { 25-hidroxivitamina D3 (25OHD) para a periodontite } \\
\text { diabética, uma complicação conhecida do diabetes. }\end{array}$ & Periodontite & N/A & $\begin{array}{l}\text { Microesferas de PLA carregadas com } 25 \mathrm{OHD} \text { pode fornecer uma } \\
\text { abordagem eficaz para o tratamento desta doença. }\end{array}$ \\
\hline $\begin{array}{l}\text { LI, Hao et al. } \\
2013 \text {. }\end{array}$ & $\begin{array}{l}\text { Estudo } \\
\text { experime } \\
\text { ntal }\end{array}$ & $\begin{array}{l}\text { Investigou experimentalmente o efeito inibitório da } 25 \\
\text { (OH) D3 na periodontite diabética em camundongos e } \\
\text { examinamos os mecanismos que podem ser } \\
\text { responsáveis por esse efeito }\end{array}$ & Periodontite & N/A & $\begin{array}{l}\text { Sugerem um possível mecanismo para explicar como a aplicação de } \\
25(\mathrm{OH}) \mathrm{D} 3 \text { poderia contribuir para a prevenção e tratamento da } \\
\text { periodontite diabética. }\end{array}$ \\
\hline $\begin{array}{l}\text { WANG, Qi et } \\
\text { al. } 2013 \text {. }\end{array}$ & & $\begin{array}{l}\text { Investigou a regulação das funções antibacterianas das } \\
\text { células de queratinócitos orais por } 25 \text {-hidroxivitamina } \\
\text { D3. }\end{array}$ & $\begin{array}{c}\text { Doenças } \\
\text { inflamatórias orais. }\end{array}$ & N/A & $\begin{array}{l}\text { Sugerem que } 25-\text { hidroxivitamina D3 é capaz de estimular a } \\
\text { produção de catelicidina e modular a função antibacteriana após a } \\
\text { desconexão do CYP24A1 nas células epiteliais orais e indicam } \\
\text { novos mecanismos de que o } 25 \mathrm{VD} 3 \text { pode aumentar a capacidade } \\
\text { antibacteriana nos queratinócitos orais. }\end{array}$ \\
\hline $\begin{array}{l}\text { ZHANG, X. } \\
\text { et al. } 2013 \text {. }\end{array}$ & $\begin{array}{l}\text { Estudo de } \\
\text { coorte }\end{array}$ & $\begin{array}{l}\text { Avaliou os níveis de Proteína de ligação à vitamina D } \\
\text { no plasma de pacientes com periodontite agressiva } \\
\text { generalizada em comparação com controles saudáveis e } \\
\text { avaliar suas correlaçôes com outros marcadores } \\
\text { inflamatórios }\end{array}$ & $\begin{array}{l}\text { Periodontite } \\
\text { agressiva } \\
\text { generalizada. }\end{array}$ & N/A & $\begin{array}{l}\text { Níveis elevados da proteína de ligação à vitamina D no plasma estão } \\
\text { associados a periodontite agressiva generelizada. }\end{array}$ \\
\hline $\begin{array}{l}\text { ANAND, } \\
\text { Sanjay et al. } \\
2014\end{array}$ & $\begin{array}{l}\text { Estudo } \\
\text { pré } \\
\text { clinico }\end{array}$ & $\begin{array}{l}\text { Estabelecer as condições sob as quais o PpIX-efeito de } \\
\text { elevação do calcitriol pode ser alcançado aumentando } \\
\text { transitoriamente a entrada de seus precursores, } \\
\text { colecalciferol e calcidiol, antes da administração de } \\
\text { terapia fotodinamica em camundongos portadores de } \\
\text { tumor. }\end{array}$ & $\begin{array}{l}\text { Carcinoma de } \\
\text { células escamosas } \\
\text { cutâneo. }\end{array}$ & N/A & $\begin{array}{l}\text { Estes resultados mostram que uma breve administração oral de } \\
\text { colecalciferol pode servir como um neoadjuvante seguro para a } \\
\text { terapia fotodinamica. }\end{array}$ \\
\hline $\begin{array}{l}\text { ANDRUKHO } \\
\text { V, Oleh et al. } \\
2014\end{array}$ & & $\begin{array}{l}\text { Examinar os efeitos da } 25(\mathrm{OH}) \text { D3, que é a forma } \\
\text { estável da vitamina D3 no sangue, e da forma } \\
\text { biologicamente ativa } 1,25(\mathrm{OH}) 2 \mathrm{D} 3 \text { na produção de } \\
\text { interleucina-6 (IL-6), interleucina-8 (IL-8) e proteína } \\
\text { quimiotática de monócitos-1 (MCP-1) por células do } \\
\text { ligamento periodontal. }\end{array}$ & Periodontite & N/A & N/A \\
\hline $\begin{array}{l}\text { BALDINI, } \\
\text { Chiara et al. } \\
2014\end{array}$ & $\begin{array}{l}\text { Estudo } \\
\text { prospectiv } \\
\quad 0\end{array}$ & $\begin{array}{l}\text { Avaliar a prevalência de hipovitaminose D na síndrome } \\
\text { de sjogren primaria (SSP) em um estágio inicial da } \\
\text { doença e avaliar seu impacto nas manifestações clínicas } \\
\text { da SSp e na atividade da doença. }\end{array}$ & $\begin{array}{l}\text { Síndrome de } \\
\text { Sjogren }\end{array}$ & N/A & $\begin{array}{l}\text { Embora o papel da hipovitaminose } D \text { na patogênese da SSP } \\
\text { permaneça controverso, os resultados deste estudo encorajam a } \\
\text { avaliação da vitamina } D \text { em subconjuntos específicos de SSP que } \\
\text { poderiam se beneficiar principalmente de uma suplementação. }\end{array}$ \\
\hline $\begin{array}{l}\text { LI, Hao et al. } \\
2014\end{array}$ & & 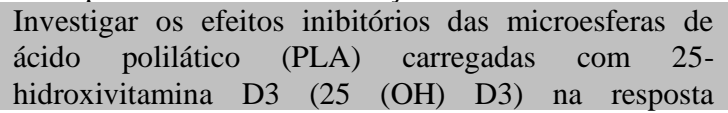 & Periodontite & N/A & $\begin{array}{l}\text { Microesferas carregadas com } 25(\mathrm{OH}) \text { D3 podem melhorar a } \\
\text { periodontite diabética ao inibir a resposta inflamatória e podem } \\
\text { fornecer uma terapia potencial para pacientes com esta doença. }\end{array}$ \\
\hline
\end{tabular}


Research, Society and Development, v. 10, n. 15, e481101523019, 2021

(CC BY 4.0) | ISSN 2525-3409 | DOI: http://dx.doi.org/10.33448/rsd-v10i15.23019

inflamatória na periodontite diabética.

\begin{tabular}{|c|c|c|c|c|c|}
\hline $\begin{array}{l}\text { ROSLI, SN } \\
\text { Zawani B. et } \\
\text { al. } 2014\end{array}$ & & $\begin{array}{l}\text { Investigar a capacidade de } 1 \alpha, 25(\mathrm{OH}) 2 \mathrm{D} 3 \text { para } \\
\text { governar a expressão de HBp17 / FGFBP-1 e FGF-2 } \\
\text { nas linhas de células OSCC. }\end{array}$ & $\begin{array}{l}\text { Carcinoma } \\
\text { espinocelular oral }\end{array}$ & N/A & $\begin{array}{l}\text { Em resumo, a capacidade de } 1 \alpha, 25(\mathrm{OH}) 2 \mathrm{D} 3 \text { para suprimir a } \\
\text { expressão de HBp17 / FGFBP-1 e FGF-2 sugere fortemente um } \\
\text { potencial terapêutico como uma droga anticâncer de alvo molecular } \\
\text { para cânceres dependentes de fator de crescimento de fibroblasto. }\end{array}$ \\
\hline $\begin{array}{l}\text { SUNDARAM } \\
\text {, Kumaran et } \\
\text { al. } 2014\end{array}$ & & $\begin{array}{l}\text { Demonstra a expressão do CYP2R1 e o mecanismo } \\
\text { regulador da transcrição de } 1,25(\mathrm{OH}) 2 \mathrm{D} 3 \text { em células } \\
\text { tumorais de carcinoma epidermóide oral. }\end{array}$ & $\begin{array}{l}\text { Carcinoma } \\
\text { espinocelular oral }\end{array}$ & N/A & $\begin{array}{l}\text { Vitamina } \mathrm{D} \text { e seus análogos podem ser potenciais agentes } \\
\text { terapêuticos para controlar a progressão de OSCC. }\end{array}$ \\
\hline $\begin{array}{l}\text { SURESH, K. } \\
\text { V. et al. } 2014\end{array}$ & $\begin{array}{l}\text { Relato de } \\
\quad \text { caso }\end{array}$ & $\begin{array}{l}\text { Relata uma combinação relativamente rara de BT } \\
\text { posterior maxilar como uma manifestação clínica de } \\
\text { HPT secundário devido a deficiência de vitamina D } \\
\text { com polidactilia, sindactilia e anomalias cardíacas. }\end{array}$ & $\begin{array}{l}\text { Tumor marro de } \\
\text { maxila posterior }\end{array}$ & N/A & $\begin{array}{l}\text { Este caso ilustra que BT de HPT secundário pode se desenvolver na } \\
\text { deficiência de vitamina D e há um resposta a suplementos de } \\
\text { vitamina D. }\end{array}$ \\
\hline
\end{tabular}

$\begin{array}{ll}\text { YUAN, Feng- } & \text { Examinamos o papel de } 1,25(\mathrm{OH}) \\ \text { Ning F. et al. } & \text { da proliferação e diferenciação em culturas }\end{array}$

2014

ARAL, Kübra

queratinócitos orais e no epitélio oral in vivo.

et al. 2015

Avaliar os efeitos da administração de vitamina K2 e /

ou vitamina D3 em adição ao tratamento periodontal convencional (raspagem e alisamento radicular) nos níveis gengivais de IL-1b e IL-10, níveis séricos de BALP e TRAP-5b e alveolar perda óssea em ratos com

periodontite induzida experimentalmente.

\begin{tabular}{|c|c|c|c|c|c|}
\hline $\begin{array}{l}\text { BOTHWELL, } \\
\text { Katelyn D. et } \\
\text { al. } 2015 \text {. }\end{array}$ & $\begin{array}{l}\text { Estudo } \\
\text { experime } \\
\text { ntal. }\end{array}$ & $\begin{array}{l}\text { Examinou o impacto de } 1,25(\mathrm{OH}) 2 \mathrm{D} 3 \text {, o metabólito } \\
\text { ativo do suplemento nutricional de vitamina D na } \\
\text { eficácia quimiopreventiva do inibidor de EGFR, } \\
\text { erlotinibe, contra carcinoma de células espinocelular } \\
\text { oral }\end{array}$ & $\begin{array}{l}\text { Carcinoma } \\
\text { espinocelular oral }\end{array}$ & N/A & $\begin{array}{l}\text { Otimizando a dose, sequência, duração da exposição e momento da } \\
\text { intervenção (pré-neoplásica vs. doença precoce vs. doença } \\
\text { estabelecida) com ambos os agentes pode ser um determinante } \\
\text { crítico da eficácia. }\end{array}$ \\
\hline $\begin{array}{l}\text { FÜGL, } \\
\text { Alexander et } \\
\text { al. } 2015\end{array}$ & $\begin{array}{l}\text { Estudo } \\
\text { pré- } \\
\text { clinico }\end{array}$ & $\begin{array}{l}\text { Conhecer o efeito da deficiência de vitamina } \mathrm{D} \text { e da } \\
\text { aplicação local na regeneração óssea alveolar. }\end{array}$ & $\begin{array}{c}\text { Regeneração óssea } \\
\text { alveolar }\end{array}$ & N/A & $\begin{array}{l}\text { A deficiência de vitamina } D \text { não prejudica necessariamente a } \\
\text { regeneração óssea na mandíbula do rato e uma única aplicação local } \\
\text { de calcitriol não melhora a cicatrização. }\end{array}$ \\
\hline
\end{tabular}

Periodontite

N/A

Os resultados fornecem forte apoio para uma função crucial para a sinalização da vitamina $\mathrm{D}$ na fisiopatologia dos queratinócitos orais.

A vitamina D3 e K2 sozinhas ou em combinação não afetaram IL-1b e IL 10 gengival, níveis séricos de B-ALP e TRAP-5b ou osso alveolar em comparação com a terapia periodontal convencional sozinha.

$2 \mathrm{mg} / \mathrm{kg}$

\section{HOSOKAWA}

, Yoshitaka et

al. 2015.

KÜHNISCH,

J. et al. 2015.
Examinou o efeito da forma hormonal da vitamina D, ligamento periodontal humano calcitriol, nas respostas inflamatórias das células do

Periodontite

HMI

coorte

Analisar a relação entre o estado sérico de 25hidroxivitamina D $(25(\mathrm{OH}) \mathrm{D})$ e dados de saúde bucal obtidos de 1.048 crianças em um acompanhamento de 10 anos.
N/A

Estes achados sugerem que a vitamina D pode modular a resposta inflamatória nos tecidos periodontais.

N/A

Concentrações séricas elevadas de $25(\mathrm{OH}) \mathrm{D}$ foram associado a melhores parâmetros de saúde bucal. 
Research, Society and Development, v. 10, n. 15, e481101523019, 2021

(CC BY 4.0) | ISSN 2525-3409 | DOI: http://dx.doi.org/10.33448/rsd-v10i15.23019

\begin{tabular}{|c|c|c|c|c|c|}
\hline $\begin{array}{l}\text { MONTAVA, } \\
\text { Marion et al. } \\
2015\end{array}$ & $\begin{array}{l}\text { Ensaio } \\
\text { clinico }\end{array}$ & $\begin{array}{l}\text { Avaliou se colecalciferol foi eficiente na reparação de } \\
\text { nervos facial de coelhos seccionados. }\end{array}$ & $\begin{array}{l}\text { Paralisia do nervo } \\
\text { facial }\end{array}$ & $200 \mathrm{UI} / \mathrm{kg} / \mathrm{dia}$ & $\begin{array}{l}\text { Colecalciferol aumenta significativamente a recuperação funcional e } \\
\text { mielinização, após } 12 \text { semanas de tratamento. }\end{array}$ \\
\hline $\begin{array}{l}\text { ABBASSY, } \\
\text { Mona A. et al. } \\
2016 .\end{array}$ & $\begin{array}{l}\text { Estudo } \\
\text { experime } \\
\text { ntal }\end{array}$ & $\begin{array}{l}\text { Avaliar o efeito da combinação intermitente de um } \\
\text { agente antirreabsortivo (calcitonina) e um agente } \\
\text { anabólico (vitamina D3) no tratamento dos efeitos } \\
\text { prejudiciais do diabetes mellitus tipo } 1 \text { (DM) na } \\
\text { formação e crescimento do osso mandibular. }\end{array}$ & $\begin{array}{l}\text { Formação e } \\
\text { crescimento } \\
\text { mandibular }\end{array}$ & N/A & $\begin{array}{l}\text { Em contraste, com a injeção de calcitonina e vitamina } \mathrm{D} 3 \text {, ambos os } \\
\text { parâmetros ósseos e a formação óssea melhoraram } \\
\text { significativamente (grupo C1D diabético) ( } \mathrm{P}<0,05) \text {. Essas } \\
\text { descobertas sugerem que esses dois hormônios podem } \\
\text { potencialmente melhorar várias propriedades ósseas. }\end{array}$ \\
\hline $\begin{array}{l}\text { CHANTARA } \\
\text { NGSU, } \\
\text { Soranun et al. } \\
2016 .\end{array}$ & $\begin{array}{c}\text { Estudo } \\
\text { transversa } \\
1\end{array}$ & $\begin{array}{l}\text { Investigou se a susceptibilidade à periodontite crônica } \\
\text { em uma população tailandesa está associada a } \\
\text { polimorfismos VDR. }\end{array}$ & Periodontite & N/A & $\begin{array}{l}\text { Os genótipos Fok I CC + CT foram associados ao aumento da } \\
\text { suscetibilidade à periodontite crônica grave, o que foi agravado } \\
\text { ainda mais quando combinado com o tabagismo. }\end{array}$ \\
\hline $\begin{array}{l}\text { FANIDI, } \\
\text { Anouar et al. } \\
2016 \text {. }\end{array}$ & $\begin{array}{l}\text { Estudo de } \\
\text { caso- } \\
\text { controle }\end{array}$ & $\begin{array}{l}\text { Além disso, nosso objetivo foi avaliar se o pré- } \\
\text { diagnóstico circulante de } 25(\mathrm{OH}) \mathrm{D} \text { está associado } \\
\text { com sobrevivência após o diagnóstico de câncer. }\end{array}$ & $\begin{array}{l}\text { Câncer de cabeça e } \\
\text { pescoço e esôfago. }\end{array}$ & N/A & $\begin{array}{l}\text { Resultados são consistentes com um papel benéfico da vitamina D } \\
\text { na etiologia do câncer de cabeça e pescoço. }\end{array}$ \\
\hline $\begin{array}{l}\text { GÜMÜŞ, } \\
\text { Pınar et al. } \\
2016 .\end{array}$ & & $\begin{array}{l}\text { Avaliar os níveis salivares de 25-hidroxivitamina D3 } \\
(25(\mathrm{OH}) \mathrm{D} 3 \text { ), prostaglandina E2 (PGE2) e TNF-alfa } \\
\text { (TNF-a) em controles gestantes, pós-parto e não } \\
\text { gestantes. }\end{array}$ & Inflamação gengival & N/A & $\begin{array}{l}\text { Parece que a gravidez tem efeito sobre parâmetros na saliva em } \\
\text { relação ao estado periodontal das mulheres. Mais estudos são } \\
\text { necessários para uma melhor compreensão do impacto das doenças } \\
\text { periodontais na gravidez ou de outra forma. }\end{array}$ \\
\hline $\begin{array}{l}\text { HAMIDIEH, } \\
\text { Amir Ali et al. } \\
2016 .\end{array}$ & $\begin{array}{l}\text { Estudo } \\
\text { duplo- } \\
\text { cego, } \\
\text { randomiz } \\
\text { ado }\end{array}$ & $\begin{array}{l}\text { Examinar a eficácia da vitamina } D \text { na prevenção de } \\
\text { mucosite oral em pacientes com anemia de Fanconi } \\
\text { submetidos a transplante de células tronco } \\
\text { hematopoieticas alogênico }\end{array}$ & $\begin{array}{l}\text { Mucosite oral em } \\
\text { paciente com } \\
\text { anemia de fanconi }\end{array}$ & $\begin{array}{l}\text { Calcitriol } \\
0,025 \mathrm{mg}\end{array}$ & $\begin{array}{l}\text { Não foi encontrado benefícios consideráveis do calcitriol na } \\
\text { prevenção de mucosite oral. Mais estudos são necessários. }\end{array}$ \\
\hline $\begin{array}{l}\text { PENONI, D. } \\
\text { C. et al.2016 }\end{array}$ & $\begin{array}{c}\text { Estudo } \\
\text { transversa } \\
1\end{array}$ & $\begin{array}{l}\text { Investigou se a osteoporose eseu tratamento pode afetar } \\
\text { a condição periodontal em mulheres idosasen. }\end{array}$ & Doença Periodontal & N/A & $\begin{array}{l}\text { Mulheres idosas com osteoporose têm maior chance de apresentar } \\
\text { periodontite, com gravidade maior do que aquelas com densidade } \\
\text { mineral óssea normal. O tratamento da osteoporose fornece proteção } \\
\text { para a periodontite. }\end{array}$ \\
\hline $\begin{array}{l}\text { SCHROTH, } \\
\text { R. J. et al. } \\
2016 .\end{array}$ & $\begin{array}{c}\text { Estudo } \\
\text { transversa } \\
1\end{array}$ & $\begin{array}{l}\text { Avaliou a relação entre o status sérico de } 25(\mathrm{OH}) \mathrm{D} \text { e } \\
\text { cárie dentária no Canadá crianças em idade escolar, de } \\
6 \text { a } 11 \text { anos, participando do Pesquisa Canadense de } \\
\text { Medidas de Saúde (CHMS). }\end{array}$ & Cárie dentária & N/A & $\begin{array}{l}\text { Sugere que há uma associação entre cáries e níveis mais baixos de } \\
\text { vitamina D no soro. }\end{array}$ \\
\hline $\begin{array}{l}\text { SHINTANI, } \\
\text { T. et al. } 2016 .\end{array}$ & & $\begin{array}{l}\text { Examinou o potencial efeito antitumoral de ED-71, um } \\
\text { análogo de } 1 \alpha, 25(\mathrm{OH}) 2 \mathrm{D} 3 \text {, para células de carcinoma } \\
\text { de células espinocelular oral in vitro e in vivo }\end{array}$ & $\begin{array}{l}\text { Carcinoma } \\
\text { espinocelular oral }\end{array}$ & N/A & $\begin{array}{l}\text { Sugere que eldecalcitol possui potencial atividade antitumoral para } \\
\text { SCCs in vitro e in vivo. }\end{array}$ \\
\hline
\end{tabular}


Research, Society and Development, v. 10, n. 15, e481101523019, 2021

(CC BY 4.0) | ISSN 2525-3409 | DOI: http://dx.doi.org/10.33448/rsd-v10i15.23019

\begin{tabular}{|c|c|c|c|c|c|}
\hline $\begin{array}{l}\text { YANIK, Saim } \\
\text { et al. } 2016 .\end{array}$ & $\begin{array}{l}\text { Estudo } \\
\text { experime } \\
\text { ntal }\end{array}$ & $\begin{array}{l}\text { Investigar o efeito da vitamina D3 na osteonecrose } \\
\text { óssea induzida após a extração dentária em ratos que } \\
\text { receberam ácido zoledrônico (Z.A). }\end{array}$ & Osteonecrose & N/A & $\begin{array}{l}\text { Conclui que existem algumas comprovações para o tratamento do } \\
\text { BRONJ com uso sistêmico de vitamina D. }\end{array}$ \\
\hline $\begin{array}{l}\text { YANG, Shih- } \\
\text { Wei et al. } \\
2016 .\end{array}$ & & $\begin{array}{l}\text { Investigar o efeito do MART-10 no potencial } \\
\text { metastático do carcinoma de células espinocelular oral } \\
\text { de cabeça e pescoço para justificar ainda mais a } \\
\text { aplicação clínica do MART-10 para o tratamento desse } \\
\text { carcinoma }\end{array}$ & $\begin{array}{l}\text { Carcinoma de } \\
\text { células } \\
\text { espinocelular oral }\end{array}$ & N/A & $\begin{array}{l}\text { O análogo de } 1 \alpha, 25(\mathrm{OH}) 2 \mathrm{D} 3 \text {, MART-10, é uma droga promissora } \\
\text { para o tratamento de carcinoma de células espinocelular oral. Mais } \\
\text { estudos clínicos são necessários. }\end{array}$ \\
\hline $\begin{array}{l}\text { AERDEN, } \\
\text { Thomas et al. } \\
2017 \text {. }\end{array}$ & $\begin{array}{l}\text { Relato de } \\
\quad \text { caso }\end{array}$ & $\begin{array}{l}\text { Apresentou o caso de um paciente masculino de } 32 \\
\text { anos com queixa de dores mandibulares recorrentes por } \\
3,5 \text { anos }\end{array}$ & $\begin{array}{l}\text { Hiperparatireoidism } \\
\text { o devido a } \\
\text { hipovitaminose D. }\end{array}$ & $25.000 \mathrm{U} / \mathrm{ml}$ & $\begin{array}{l}\text { Embora cause principalmente } \\
\text { hiperparatireoidismo secundário } \\
\text { mandibular e hipercorticalização. }\end{array}$ \\
\hline $\begin{array}{l}\text { DU, J. et al. } \\
2017\end{array}$ & $\begin{array}{l}\text { Estudo } \\
\text { experime } \\
\text { ntal }\end{array}$ & $\begin{array}{l}\text { Explorar a função protetora da vitamina D (VD) / } \\
\text { receptor da vitamina D (VDR) no desenvolvimento do } \\
\text { líquen plano oral (LPO) e elaborar seu mecanismo } \\
\text { subjacente. }\end{array}$ & Liquen plano & N/A & $\begin{array}{l}\text { Sugere que } 1,25(\mathrm{OH}) 2 \mathrm{D} 3 \text { desempenha um papel antiinflamatório } \\
\text { no liquen plano oral ao mediar a via de sinalização de NF-kB, mas } \\
\text { não a via de sinalização de AP-1 com uma maneira dependente de } \\
\text { VDR, prevendo suplemento de vitamina D pode ser uma estratégia } \\
\text { potencial para a gestão OLP. }\end{array}$ \\
\hline $\begin{array}{l}\text { KILINÇ, } \\
\text { Adnan et al. } \\
2017 .\end{array}$ & $\begin{array}{l}\text { Relato de } \\
\text { caso. }\end{array}$ & $\begin{array}{l}\text { Paciente de fiborma ossificante envolvendo a maxila e } \\
\text { a mandíbula bilateral em uma Mulher de } 37 \text { anos. }\end{array}$ & Fibroma Ossificante & N/A & $\begin{array}{l}\text { Múltiplas ocorrências do tumor em } 3 \text { quadrantes e a deficiência de } \\
\text { vitamina D que a acompanha são os aspectos importantes deste } \\
\text { relatório, embora relatórios adicionais sejam necessários para } \\
\text { associar vários OF diretamente com a deficiência de vitamina D. }\end{array}$ \\
\hline $\begin{array}{l}\text { Morr } \\
\text { Verenzuela, } \\
\text { Claudia S., et } \\
\text { al. } 2017 .\end{array}$ & $\begin{array}{l}\text { Estudo } \\
\text { retrospect } \\
\quad \text { ivo }\end{array}$ & $\begin{array}{l}\text { Determinar a associação entre síndrome da boca } \\
\text { ardente e anormalidades laboratoriais de vitaminas, } \\
\text { minerais, hormônios e glicose específicos. }\end{array}$ & $\begin{array}{l}\text { Síndrome da boca } \\
\text { ardente }\end{array}$ & N/A & $\begin{array}{l}\text { Em pacientes com sintomas de síndrome da boca ardente, nossos } \\
\text { resultados sugerem que é razoável triagem para glicose no sangue } \\
\text { em jejum, vitamina D (D } 2 \text { e D 3), vitamina B } 6 \text {, zinco, vitamina } \\
\text { B } 1 \text { e TSH }\end{array}$ \\
\hline $\begin{array}{l}\text { NAKASHYA } \\
\text { N, V. et al. } \\
2017 \text {. }\end{array}$ & & $\begin{array}{l}\text { Determinar os efeitos de } 1,25 \mathrm{D} 3 \text { ou um análogo não } \\
\text { calcêmico, 20-hidroxivitamina D3- } 20(\mathrm{OH}) \mathrm{D} 3 \text { ou } \\
20 \mathrm{D} 3 \text { - na produção de IL-6 e IL-8 estimulada por IL- } \\
1 \beta \text { e NF- } \kappa \mathrm{B} \text { e ativação de MAPK / AP-1, por } \\
\text { fibroblastos gengivais humanos. }\end{array}$ & Periodontite & N/A & $\begin{array}{l}\text { Os resultados sugerem que a aplicação tópica de ligantes do receptor } \\
\text { da vitamina } \mathrm{D} \text { pode ser útil no tratamento local da periodontite, ao } \\
\text { mesmo tempo em que reduz os efeitos adversos sistêmicos. }\end{array}$ \\
\hline $\begin{array}{l}\text { SHINTANI, } \\
\text { T. et al. } 2017 .\end{array}$ & & $\begin{array}{l}\text { Investigou os efeitos de eldecalcitol, um análogo da } \\
\text { vitamina D3 (VD) em linhas de células OSCC em } \\
\text { cultura sem soro }\end{array}$ & $\begin{array}{l}\text { Carcinoma } \\
\text { espinocelular oral }\end{array}$ & N/A & $\begin{array}{l}\text { Sugere que eldecalcitol é um potencial agente anticancerígeno para } \\
\text { OSCC. }\end{array}$ \\
\hline $\begin{array}{l}\text { BAHRAMIA } \\
\text { N, Ayla et al. } \\
2018\end{array}$ & $\begin{array}{c}\text { Estudo } \\
\text { transversa } \\
1\end{array}$ & $\begin{array}{l}\text { Comparar as concentrações séricas e níveis salivares de } \\
\text { vitamina D em pacientes com estomatite aftosa } \\
\text { recorrente e indivíduos saudáveis. }\end{array}$ & $\begin{array}{l}\text { Estomatite aftosa } \\
\text { recorrente }\end{array}$ & N/A & $\begin{array}{l}\text { Os níveis séricos de vitamina } \mathrm{D} \text { em indivíduos com estomatite aftosa } \\
\text { recorrente foram significativamente menores do que em indivíduos } \\
\text { saudáveis. }\end{array}$ \\
\hline $\begin{array}{l}\text { DUDDING, } \\
\text { Tom et al. } \\
2018 \text {. }\end{array}$ & $\begin{array}{l}\text { Estudo } \\
\text { randomiz } \\
\text { ado. }\end{array}$ & $\begin{array}{l}\text { Avaliar a associação causal entre a vitamina } \mathrm{D} \text { e o risco } \\
\text { de câncer oral e orofaríngeo e estimar o tamanho de } \\
\text { qualquer efeito usando a randomização mendeliana. }\end{array}$ & $\begin{array}{l}\text { Câncer oral e } \\
\text { orofaríngeo. }\end{array}$ & N/A & $\begin{array}{l}\text { Sugere que um efeito protetor clinicamente relevante do } 25 \mathrm{OHD} \text { no } \\
\text { risco de câncer oral e orofaríngeo é improvável e a suplementação da } \\
\text { população geral com } 25 \mathrm{OHD} \text { é improvável que seja benéfica na } \\
\text { prevenção desses cânceres. }\end{array}$ \\
\hline
\end{tabular}


Research, Society and Development, v. 10, n. 15, e481101523019, 2021

XIAO, Ting-

Ting et al

2018

\section{ZHANG, P. et al. 2018 \\ ZHOU, Xinyi \\ et al. 2018.}

\section{Estudo} experima

Avaliar os efeitos potenciais da aspirina combinada com vitamina D3 na proliferação celular e apoptose em células de câncer oral.

BI, Estudo Avaliou o efeito supressor da administração de

Chun-Sheng experime calcitriol na perda óssea alveolar em animais com

et al. 2019. ntal periodontite induzida por LPS e para investigar como a administração de calcitriol pode influenciar as fases destrutivas do periodontite.

GE, Xuejun et Explorou o mecanismo pelo qual a sinalização da al. 2019. vitamina D / VDR regula a inflamação nos queratinócitos orais

HAN, Jing et Investigar os efeitos da vitamina D em modelos de al. 2019.

HUANG,

Zixian et al.

2019. ratos com doença pulmonar obstrutiva crônica e periodontite.

Relatar que a vitamina $\mathrm{D}$ pode promover a cisplatina sensibilidade em células OSCC e tumores xenoenxertados

KETHARAN Estudo Avaliar o nível ósseo radiográfico e níveis séricos de ATHAN, transversa VitD em pacientes com periodontite de étnia Vimalan etal. 11 norueguesa e tamil e seus respectivos controles 2019.

LI, Hao et al. saudáveis.

2019.

Ensaio

clinico
Explorar o efeito do VD3 tratamento em periodontite e

AhR / NF- $\kappa B$ / NLRP3 via inflamassoma no epitélio gengival de Camundongos C57BL / 6 de tipo selvagem com periodontite experimental induzida pela inoculação de $P$. gingivalis

A aspirina e a vitamina D3 têm atividade biológica contra duas linhagens de células OSCC humanas e sua atividade é sinérgica ou aditiva quando duas drogas são utilizadas em combinação com concentrações terapêuticas. A combinação de aspirina e vitamina D3 pode ser uma abordagem eficaz para induzir a morte celular no OSCC.

Carcinoma de

células escamosa

$$
\text { oral. }
$$

Periodontite

Fornece evidências de uma regulação positiva de PTPN2 contra periodontite em T2D após o tratamento com vitamina D3 e os resultados implicam que a aplicação dessa vitamina pode servir como um tratamento alternativo potencial para prevenir doença periodontal.

Periodontite

N/A

A ingestão adicional de vitamina D3 aliviou notavelmente a destruição do tecido periodontal.

Periodontite

N/A

Os achados sugerem que o calcitriol pode ser usado para inibir a perda óssea na periodontite experimental, provavelmente por meio da regulação da polarização local e sistêmica das células Th.

Liquen plano oral.

N/A

Revela um papel não reconhecido da sinalização da vitamina D / VDR na regulação de citocinas em queratinócitos orais e revela sua base molecular.

Periodontite

N/A

A suplementação de vitamina $D$ pode ser uma nova abordagem clínica para o tratamento da doença pulmonar obstrutiva crônica e periodontite.

Carcinoma

N/A

espinocelular oral

Revela que a vitamina pode melhorar a quimioterapia com cisplatina e sugere que a vitamina $D$ deve ser fornecida durante a quimioterapia; Contudo mais estudos clínicos de acompanhamento são necessários.

Periodontite N/A Os níveis de VitD mostraram associação significativa com a presença de periodontite, expressa pela perda óssea radiográfica, em todos os pacientes combinados.

Periodontite

N/A

A atenuação desta doença periodontal pode se correlacionar com a regulação da via do inflamassoma AhR / NF-kB / NLRP3 por VD3. 
Research, Society and Development, v. 10, n. 15, e481101523019, 2021

MENZEL,

Lorenzo P. et

al.2019.

NASREEN,

Saba et al.

2019

QIN, Xiurong Estudo de Examinou os efeitos dos polimorfismos do gene do

et al.2019. caso-

controle receptor da vitamina D (VDR) e do ambiente do gene interações sobre a etiologia e suscetibilidade à cárie em crianças chinesas de 3 a 5 anos.

THAKUR,

Moni. 2019

Relato de

caso.

Relatar dois casos de

VINCENT-

Ensaio

CHONG, Vui pré-

King et al.

2019.

WANG, Qian - Estudo

et al. 2019.

Estudo

1

Elucidar a relação entre a deficiência de $25(\mathrm{OH}) \mathrm{D} 3$ e

gravidade de periodontite em diabéticos tipo 2 , bem como os mecanismos potenciais.

a defesa inata contra o desenvolvimento da doença

Estimar e avaliar a massa óssea alveolar por meio de índices radomorfométricos em mulheres na pósmenopausa e sua correlação com a vitamina D3 sérica.

1

\section{Determinar o impacto do estágio de intervenção na}

\section{Doença Periodontal}

\section{Massa óssea}

alveoalar.

\section{Cárie na primeira \\ infância.}

Manifestações orais

e alopecia em

pessoas com

raquistismo

dependente de

vitamina D tipo $2^{\mathrm{a}}$.

Carcinoma

espinocelular oral

Periodontite em

pacientes diabeticos

\section{ZHAO, Bin et} al. 2019

\section{DESANTIS,}

Kara A. et al.

2020

GAO,

Weiminsaio

Weimin et al. randomiz

2020 .
Explorou o papel do miR-802 em queratinócitos orais apoptose, bem como o mecanismo de proteção da vitamina Sinalização D / VDR contra OLP.

Para obter uma visão sobre o papel potencial do receptor de vitamina D no câncer salivar, avaliaram os efeitos da vitamina $D$ in vivo e in vitro.

Avaliar a eficácia e segurança da suplementação de vitamina $\mathrm{D}$ nas bolsas residuais moderadas e profundas ado, após a terapia periodontal não cirúrgica.
N/A

A deficiência de vitamina D em camundongos contribui para a DP, recapitulando a associação observada em humanos, e fornece um modelo único para estudar o desenvolvimento da DP.

A alta prevalência geral $(90 \%)$ de deficiência de vitamina D também foi observada nos indivíduos do estudo.

Polimorfismos VDR não podem ser usados como marcadores para a identificação de crianças chinesas com risco aumentado de cárie dentária, quando combinada com fatores ambientais. Estudos futuros são necessários para replicar essas descobertas iniciais e melhor avaliar o risco de cárie em dentes decíduos.

N/A O diagnóstico precoce e o tratamento imediato corrigem o metabolismo ósseo perturbado e as deformidades dentárias e melhora a qualidade de vida.

N/A

Resultados mostram que os efeitos do calcitriol na carcinogênese oral são criticamente influenciados por o estágio de intervenção e a duração da exposição e fornecem a base para explorar o potencial do calcitriol para prevenção do OSCC no ambiente clínico

A eficiência de VD 3 pode ser um fator de risco para periodontite em diabéticos tipo 2. Níveis anormais de glicose no sangue e IL-1 $\beta$ poderiam ser marcadores de risco importantes para deficiência de colecalciferol em periodontite em diabéticos tipo 2 . O mecanismo proposto pode envolver o efeito de $25(\mathrm{OH})$ D 3 defi-ciência em enfraquecer a atividade transcricional de periodontite em diabéticos tipo 2, que agravaria ainda mais a inflamação periodontal em T2DCP.

$\begin{array}{ll}\text { Líquen Plano Oral N/A } & \begin{array}{l}\text { Sugere que a sinalização de vitamina D / VDR suprime a apoptose } \\ \text { de queratinócitos orais por direcionamento miR-802. }\end{array}\end{array}$

Câncer de glândula

$$
\text { salivar. }
$$

N/A queratinócitos orais por direcionamento miR-802.

Periodontite

2.000 (IU) / d

vitamina $\mathrm{D} 3$,

$1000 \mathrm{IU} / \mathrm{d}$

vitamina D3 ou placebo.
Sugere que 1,25D altera progenitores relevantes para o câncer e

Embora diferenças estatisticamente significativas tenham sido observadas em favor da suplementação de vitamina $D$, a magnitude do tamanho do efeito tendeu a ser modesta com relevância clínica limitada e a eficácia e segurança em longo prazo justificam uma investigação mais aprofundada. marcadores de diferenciação na glândula salivar. 
Research, Society and Development, v. 10, n. 15, e481101523019, 2021

(CC BY 4.0) | ISSN 2525-3409 | DOI: http://dx.doi.org/10.33448/rsd-v10i15.23019

\begin{tabular}{|c|c|c|c|c|c|}
\hline & $\begin{array}{l}\text { controlad } \\
\text { o por } \\
\text { placebo }\end{array}$ & & & & \\
\hline $\begin{array}{l}\text { TORRUNGR } \\
\text { UANG, Kitti } \\
\text { et al. } 2020\end{array}$ & $\begin{array}{l}\text { Estudo } \\
\text { Transvers } \\
\text { al }\end{array}$ & $\begin{array}{l}\text { Investigou o efeito do polimorfismo FokI do receptor } \\
\text { de vitamina D (VDR) e suas interações com fumar / } \\
\text { beber nas proporções de patógenos periodontais e } \\
\text { gravidade da periodontite. }\end{array}$ & Periodontite & N/A & $\begin{array}{l}\text { Demonstrou que o polimorfismo VDR FokI interagiu com o } \\
\text { tabagismo e, em menor extensão, com o beber na determinação das } \\
\text { proporções de P. gingivalis e gravidade da periodontite em uma } \\
\text { população tailandesa. }\end{array}$ \\
\hline
\end{tabular}

N/A - não aplicável.

UI - Unidades internacionais.

Fonte: Autores. 


\section{Discussão}

A vitamina D3 é um pró-hormônio solúvel em gordura que é conhecida principalmente por regular a homeostase do cálcio e do fosfato, ela pode ser obtida por meios endógenos, através da sintetização da luz solar na pele ou exógenos, por meio de alimentos, sendo que, sua contribuição por meios exógenos, é pequena (Aral et al., 2015; Kühnisch et al., 2015). Após sua metabolização no fígado e nos rins o colecalciferol é a forma biologicamente ativa dessa vitamina (Anand et al., 2014).

Fundamentado nos resultados, foram encontrados em nosso estudo, associações do colecalciferol com diversas patologias orais, sendo elas, o câncer de cabeça e pescoço, gengivite, periodontite, cárie, manifestações orais e faciais em pessoas com raquitismo e doenças autoimune, sendo algumas com mais evidencias que outras.

A utilização do colecalciferol como um agente antitumoral e quimiopreventivo tem mostrado efeitos promissores (Gedlicka et al., 2005; Rosli; Shintani, 2014; Sundaram et al., 2014; Huang, Zixian et al., 2019; Desantis et al., 2020). O estudo de Gedlicka, et al. (2006) mostra em seu trabalho que, o colecalciferol medeia a inibição de crescimento por meio de inibidores em linhas de células de câncer de cabeça e pescoço, nos sugerindo portanto, seu efeito antitumoral.

As células tumorais humanas expressam níveis elevados de CYP2R1, uma enzima que converte a vitamina $\mathrm{D}$, e essa vitamina modula os níveis de CYP2R1 nas células tumorais, expondo consequentemente que a falta de vitamina D3 aumente o risco de câncer oral e mostra, portanto que, os análogos da vitamina D podem ser prováveis agentes terapêuticos para conter o curso do carcinoma espinocelular (Rosli \& Shintani, 2014; Sundaram et al., 2014). O estudo caso-controle de Fanidi et al. (2016) avaliou se a vitamina D circulante está associada a sobrevida após o diagnóstico de câncer, relata que houve uma diminuição perceptível do risco de câncer assim como uma melhoria na sobrevida para os pacientes com níveis plasmáticos mais altos de colecalciferol mostrando que ele tem papel benéfico na etiologia do câncer de cabeça e pescoço.

Huang, et al. (2019) indicam que a vitamina D melhora a sensibilidade a cisplatina (medicamento antineoplásico) quando utilizando junto ao tratamento quimioterápico, propondo que a vitamina $\mathrm{D}$ deveria ser tomada após o início da quimioterapia, porém, mais estudos clínicos de acompanhamento são necessários.

Já Xiao, et al. (2018) dizem que, a combinação de aspirina e vitamina D pode ser uma abordagem eficaz para inibir a morte celular no carcinoma espinocelular oral enquanto Anand, et al. (2014) também trazem uma associação da vitamina D, mostrando em seus resultados que uma breve ministração oral de colecalciferol pode servir como um neoadjuvante seguro para a terapia fotodinâmica.Portanto o colecalciferol tem mostrado resultados promissores em estudos para sua utilização como agente antitumoral e quimiopreventivo em canceres de cabeça e pescoço porém, ainda não se tem evidências concretas.

O colecalciferol vem sendo estudado a muitos anos, Ferguson e Hartles, (1964) e Hartles e Shapiro, (1966) investigaram em seus estudos as mudanças que ocorrem na formação da dentina e no padrão de mineralização de dietas com deficiência de vitamina D3 em seus estudos.

Segundo Berdal, et al. (1987) a vitamina D tem uma função nos acontecimentos iniciais do desenvolvimento do dente, sendo eles a morfogênese, histodiferenciação e citodiferenciação de células pulpares, bem como no esmalte e mineralização da dentina.

No estudo transversal de Schroth et al.(2016), foi avaliando a relação entre os níveis séricos de Vitamina D3 e a cárie dentária em crianças em idade escolar no Canadá, verificou que quando em níveis < ou igual a $70 \mathrm{nmol} / \mathrm{L}$ de vitamina D3 se tem 39\% menos chance de cárie, da mesma maneira que em um estudo de coorte, foi verificado que menores concentrações séricas de vitamina D3 foram associadas a uma maior probabilidade de restaurações relacionadas a hipomineralização molarincisivo e também cárie em crianças de 10 anos de idade. Nosso estudo constatou, portanto uma associação entre cárie e níveis séricos baixos de vitamina D3 no qual podemos averiguar que a preservação de bons níveis de colecalciferol associado a recomendações de suplementação durante a infância, poderiam ser um coadjuvante na diminuição à carie dentária quando associado a uma boa higiene oral, a partir dos dados levantados. 
Chaussain et al. (2007) verificaram que, o raquitismo hipofosfatêmico familiar atinge principalmente a dentina circumpulpar do dente, restringindo o crescimento e ocasionando em uma dentina porosa com tendência à invasão bacteriana. Foi observado também associações em relatos de casos com pacientes com raquitsimos hipofosfatemico familiar à tendência a manifestações orais e deformidades estruturais dos dentes (Bender \& Naidorf, 1986; Beltes \& Zachou, 2012; Narayan Biswal et al., 2019 Murayama et al., 2000).

Os dados encontrados nesse trabalho sugerem que, que devido ao raquitismo ser uma doença que afeta a metabolização da vitamina $\mathrm{D}$, muitas manifestações orais e crânio faciais estão presentes nesses pacientes, expondo, portanto o importante papel muito dessa vitamina no desenvolvimento e manutenção dessa estruturas pois, quando diagnosticadas precocemente e realizado o tratamento com sua suplementação, o prognóstico de pacientes com raquitismo são muito favoráveis.

A periodontite é uma doença inflamatória muito comum, que induz uma perda óssea alveolar induzida pela resposta imune ao hospedeiro, nosso estudo mostrou associações entre periodontite e níveis baixos de colecalciferol assim como, verificamos seus efeitos anti-inflamatórios. Em seu ensaio clinico longitudinal Bashutski, et al. (2011) diz que ao se realizar uma cirurgia periodontal tendo os níveis de colecalciferol abaixo do normal no momento da cirurgia isso afeta negativamente os resultados do tratamento por até 1 ano, assim como outros autores relatam que deficiência dessa vitamina favorece a doença periodontal (Ketharanathan et al., 2019; Menzel et al., 2019). Hosokawa, et al (2015) relata em seu trabalho o papel da vitamina D3 como modulador da resposta inflamatória nos tecidos periodontais.

Liu, et al. (2009) avaliaram em seu estudo se havia associação entre concentrações plasmáticas de colecalciferol e periodontite agressiva crônica e verificou que, os níveis plasmáticos foram maiores em pacientes com periodontite do que nos controles saúdaveis e Liu et al., (2010) verificaram que, ao se iniciar a terapia periodontal, os níveis plasmáticos dessa vitamina foram reduzidos assim como, Zhang, et al. (2013) também verificaram uma alta concentração plasmática da proteína de ligação a vitamina $\mathrm{D}$ em pacientes com periodontite agressiva generalizada, logo nosso estudo verificou então, um papel do colecalciferol na inflamação periodontal.

A relação da dose da vitamina para exercer um papel anti-inflamatório em alguns estudos como Hiremath et al., (2013) em seu estudo clinico randomizado duplo-cego controlado por placebo observaram que há um efeito anti-inflamatório dose dependente da vitamina D na gengivite sendo que os resultados aparecem expressivos na dose de 2.000 UI (Unidades internacionais) de vitamina $\mathrm{D}$.

Gao et al., (2020) em um estudo clinico randomizado duplo-cego controlado por placebo diseram que a suplementação traz uma melhora significativa porem limitada da periodontite nesses pacientes, porem devido ao curto tempo desse estudo seria necessário verificar esse benefício em estudos com maior duração de tempo.

Sendo assim, pode-se observar que sua suplementação é uma forma segura e eficaz em doses variáveis de $500 \mathrm{UI} / \mathrm{d}$ a $2.000 \mathrm{UI} / \mathrm{d}$ tendo essa última dose um efeito mais precoce e mantendo o colecalciferol em níveis séricos normais, benefícios podem ser alcançados com relação a prevenção e tratamento da periodontite e gengivite.

$\mathrm{Du}$, et al (2017) sugerem que essa vitamina tem um efeito anti-inflamatório no líquen plano oral (LPO) enquanto Zhao, et al. (2019) e Ge, et al. (2019) mostram que mais testes com a vitamina D em ambientes clínicos e experimentais podem ser benéficos para o controle do LPO.

Kribbs (1992) mediu em seu trabalho a massa óssea mandibular em mulheres com osteoporose pós menopausa e avaliou se o colecalciferol aumentou a massa óssea mandibular por um período de 2 anos o qual o mesmo conclui que a variação na quantidade de mudança na massa óssea mandibular não foi relacionada à administração de colecalciferol, em contraste Spolidorio et al., (2010) conclui que a terapia intermitente previne a perda óssea alveolar. 
Krall et al., (2001) em seu ensaio duplo cego randomizado controlado propuseram que há um efeito benéfico na retenção dentária quando níveis de ingestão de cálcio e vitamina D3 destinados a prevenir osteoporose são suplementados.

Verificamos também a associação do colecalciferol outras patologias orais porém essas em menor escala os quais observamos sua participação quando em níveis séricos baixos nessa patologias, assim como seu papel regulador.

\section{Conclusão}

Conclui se que, com base nos resultados, a manutenção de níveis séricos ideais de colecalciferol é muito importante para a preservação e manutenção saúde bucal assim como para a saúde sistêmica, e seu o entendimento e sua suplementação quando necessária devem ser realizadas de maneira assertiva, sendo esse um importante modulador imunológico. Seus efeitos como agente anti-inflamatório, antineoplásico e/ou quimiopreventivos são bastante promissores, devendo então mais estudos serem realizados acerca do tema para validar sua utilização nos mais diversos campus da odontologia e da medicina moderna, podendo assim, de uma maneira facilitada, melhorar e avançar no controle de patologias ainda não completamente compreendidas.

\section{Referências}

Abbassy, M. A., Watari, I., Bakry, A. S., Ono, T., \& Hassan, A. H. (2016). Calcitonin and vitamin D3 have high therapeutic potential for improving diabetic mandibular growth. International journal of oral science, 8(1), 39-44. https://doi.org/10.1038/ijos.2015.47

Abe, K., Ooshima, T., Lily, T. S., Yasufuku, Y., \& Sobue, S. (1988). Structural deformities of deciduous teeth in patients with hypophosphatemic vitamin Dresistant rickets. Oral surgery, oral medicine, and oral pathology, 65(2), 191-198. https://doi.org/10.1016/0030-4220(88)90165-x

Abe, M., Akeno, N., Ohida, S., \& Horiuchi, N. (1998). Inhibitory effects of 1,25-dihydroxyvitamin D3 and 9-cis-retinoic acid on parathyroid hormone-related protein expression by oral cancer cells (HSC-3). The Journal of endocrinology, 156(2), 349-357. https://doi.org/10.1677/joe.0.1560349

Abe, K., Ooshima, T., Sobue, S., \& Moriwaki, Y. (1989). The crystallinity of human deciduous teeth in hypophosphataemic vitamin D-resistant rickets. Archives of oral biology, 34(5), 365-372.

Aerden, T., Grisar, K., Nys, M., \& Politis, C. (2018). Secondary hyperparathyroidism causing increased jaw bone density and mandibular pain: a case report. Oral surgery, oral medicine, oral pathology and oral radiology, 125(3), e37-e41. https://doi.org/10.1016/j.oooo.2017.11.020

Agha-Hosseini, F., Mirzaii-Dizgah, I., \& Mirjalili, N. (2013). Unstimulated whole saliva 25-hydroxycholecalciferol in patients with xerostomia in menopausal women. Aging clinical and experimental research, 25(2), 147-151. https://doi.org/10.1007/s40520-013-0023-z

Anand, S., Rollakanti, K. R., Horst, R. L., Hasan, T., \& Maytin, E. V. (2014). Combination of oral vitamin D3 with photodynamic therapy enhances tumor cell death in a murine model of cutaneous squamous cell carcinoma. Photochemistry and photobiology, 90(5), 1126-1135. https://doi.org/10.1111/php.12286

Andrukhov, O., Andrukhova, O., Hulan, U., Tang, Y., Bantleon, H. P., \& Rausch-Fan, X. (2014). Both 25-hydroxyvitamin-D3 and 1,25-dihydroxyvitamin-D3 reduces inflammatory response in human periodontal ligament cells. PloS one, 9(2), e90301. https://doi.org/10.1371/journal.pone.0090301

Aral, K., Alkan, B. A., Saraymen, R., Yay, A., Şen, A., \& Önder, G. Ö. (2015). Therapeutic effects of systemic vitamin k2 and vitamin d3 on gingival inflammation and alveolar bone in rats with experimentally induced periodontitis. Journal of periodontology, 86(5), 666-673. https://doi.org/10.1902/jop.2015.140467

Bahramian, A., Falsafi, P., Abbasi, T., Ghanizadeh, M., Abedini, M., Kavoosi, F., Kouhsoltani, M., Noorbakhsh, F., Dabbaghi Tabriz, F., Rajaeih, S., \& Rezaei, F. (2018). Comparing Serum and Salivary Levels of Vitamin D in Patients with Recurrent Aphthous Stomatitis and Healthy Individuals. Journal of dentistry (Shiraz, Iran), 19(4), 295-300.

Baldini, C., Delle Sedie, A., Luciano, N., Pepe, P., Ferro, F., Talarico, R., Tani, C., \& Mosca, M. (2014). Vitamin D in "early" primary Sjögren's syndrome: does it play a role in influencing disease phenotypes?. Rheumatology international, 34(8), 1159-1164. https://doi.org/10.1007/s00296-013-2872-3

Bashutski, J. D., Eber, R. M., Kinney, J. S., Benavides, E., Maitra, S., Braun, T. M., Giannobile, W. V., \& McCauley, L. K. (2011). The impact of vitamin D status on periodontal surgery outcomes. Journal of dental research, 90(8), 1007-1012. https://doi.org/10.1177/0022034511407771

Beltes, C., \& Zachou, E. (2012). Endodontic management in a patient with vitamin D-resistant Rickets. Journal of endodontics, 38(2), 255-258. https://doi.org/10.1016/j.joen.2011.10.025

Bender, I. B., \& Naidorf, I. J. (1985). Dental observations in vitamin D-resistant rickets with special reference to periapical lesions. Journal of endodontics, 11(11), 514-520. https://doi.org/10.1016/S0099-2399(85)80225-9

Berdal, A., Balmain, N., Cuisinier-Gleizes, P., \& Mathieu, H. (1987). Histology and microradiography of early post-natal molar tooth development in vitaminD deficient rats. Archives of oral biology, 32(7), 493-498. https://doi.org/10.1016/s0003-9969(87)80010-9 
Bi, C. S., Wang, J., Qu, H. L., Li, X., Tian, B. M., Ge, S., \& Chen, F. M. (2019). Calcitriol suppresses lipopolysaccharide-induced alveolar bone damage in rats by regulating T helper cell subset polarization. Journal of periodontal research, 54(6), 612-623. https://doi.org/10.1111/jre.12661

Bothwell, K. D., Shaurova, T., Merzianu, M., Suresh, A., Kuriakose, M. A., Johnson, C. S., Hershberger, P. A., \& Seshadri, M. (2015). Impact of Short-term 1,25-Dihydroxyvitamin D3 on the Chemopreventive Efficacy of Erlotinib against Oral Cancer. Cancer prevention research (Philadelphia, Pa.), 8(9), 765776. https://doi.org/10.1158/1940-6207.CAPR-14-0454

Chantarangsu, S., Sura, T., Mongkornkarn, S., Donsakul, K., \& Torrungruang, K. (2016). Vitamin D receptor gene polymorphism and smoking in the risk of chronic periodontitis. Journal of periodontology, 87(11), 1343-1351.

Chaussain-Miller, C., Sinding, C., Septier, D., Wolikow, M., Goldberg, M., \& Garabedian, M. (2007). Dentin structure in familial hypophosphatemic rickets: benefits of vitamin D and phosphate treatment. Oral diseases, 13(5), 482-489.

Dalirsani, Z., Farajnia, S., Javadzadeh, Y., Mehdipour, M., \& Koozegari, S. (2012). The effects of 5-fluorouracil alone and in combination with 13-cis retinoic acid and vitamin D3 on human oral squamous cell carcinoma lines. The journal of contemporary dental practice, 13(3), 345-350. https://doi.org/10.5005/jpjournals-10024-1149

Dawson, S. J., Murray, R. M., \& Rischin, D. (2006). Hypocalcemia associated with bone metastases in a patient with salivary-gland carcinoma. Nature clinical practice. Oncology, 3(2), 104-107. https://doi.org/10.1038/ncponc0405

DeSantis, K. A., Robilotto, S. L., Matson, M., Kotb, N. M., Lapierre, C. M., Minhas, Z., Leder, A. A., Abdul, K., Facteau, E. M., \& Welsh, J. (2020). VDR in salivary gland homeostasis and cancer. The Journal of steroid biochemistry and molecular biology, 199, 105600. https://doi.org/10.1016/j.jsbmb.2020.105600

Descroix, V., Kato, S., Lézot, F., \& Berdal, A. (2010). Physiopathology of dental rickets in vitamin D receptor-ablated mice. Journal of dental research, 89(12), 1427-1432. https://doi.org/10.1177/0022034510379603

Do, J. E., Kwon, S. Y., Park, S., \& Lee, E. S. (2008). Effects of vitamin D on expression of Toll-like receptors of monocytes from patients with Behcet's disease. Rheumatology (Oxford, England), 47(6), 840-848. https://doi.org/10.1093/rheumatology/ken109

Du, J., Li, R., Yu, F., Yang, F., Wang, J., Chen, Q., Wang, X., Zhao, B., \& Zhang, F. (2017). Experimental study on 1,25(OH) $)_{2} \mathrm{D}_{3}$ amelioration of oral lichen planus through regulating NF-kB signaling pathway. Oral diseases, 23(6), 770-778. https://doi.org/10.1111/odi.12659

Dudding, T., Johansson, M., Thomas, S. J., Brennan, P., Martin, R. M., \& Timpson, N. J. (2018). Assessing the causal association between 25-hydroxyvitamin $\mathrm{D}$ and the risk of oral and oropharyngeal cancer using Mendelian randomization. International journal of cancer, 143(5), 1029-1036. https://doi.org/10.1002/ijc.31377

Fanidi, A., Muller, D. C., Midttun, Ø., Ueland, P. M., Vollset, S. E., Relton, C., Vineis, P., Weiderpass, E., Skeie, G., Bru stad, M., Palli, D., Tumino, R., Grioni, S., Sacerdote, C., Bueno-de-Mesquita, H. B., Peeters, P. H., Boutron-Ruault, M. C., Kvaskoff, M., Cadeau, C., Huerta, J. M., Johansson, M. (2016). Circulating vitamin D in relation to cancer incidence and survival of the head and neck and oesophagus in the EPIC cohort. Scientific reports, 6, 36017. https://doi.org/10.1038/srep36017

Femiano, F., Gombos, F., Scully, C., Battista, C., Belnome, G., \& Esposito, V. (2001). Oral leukoplakia: open trial of topical therapy with calcipotriol compared with tretinoin. International journal of oral and maxillofacial surgery, 30(5), 402-406. https://doi.org/10.1054/ijom.2001.0107

Ferguson, H. W., \& Hartles, R. L. (1964). The effect of vitamin D on the dentine of the incisor teeth and on the alveolar bone of young rats maintained on diets deficient in calcium or phosphorus. Archives of oral biology, 9(4), 447-IN19.

Fink M. (2011). Vitamin D deficiency is a cofactor of chemotherapy-induced mucocutaneous toxicity and dysgeusia. Journal of clinical oncology : official journal of the American Society of Clinical Oncology, 29(4), e81-e82. https://doi.org/10.1200/JCO.2010.31.5317

Fügl, A., Gruber, R., Agis, H., Lzicar, H., Keibl, C., Schwarze, U. Y., \& Dvorak, G. (2015). Alveolar bone regeneration in response to local application of calcitriol in vitamin D deficient rats. Journal of clinical periodontology, 42(1), 96-103. https://doi.org/10.1111/jcpe.12342

Gao, W., Tang, H., Wang, D., Zhou, X., Song, Y., \& Wang, Z. (2020). Effect of short-term vitamin D supplementation after nonsurgical periodontal treatment: A randomized, double-masked, placebo-controlled clinical trial. Journal of periodontal research, 55(3), 354-362. https://doi.org/10.1111/jre.12719

Ge, X., Wang, L., Li, M., Xu, N., Yu, F., Yang, F., Li, R., Zhang, F., Zhao, B., \& Du, J. (2019). Vitamin D/VDR signaling inhibits LPS-induced IFN $\gamma$ and IL$1 \beta$ in Oral epithelia by regulating hypoxia-inducible factor-1 $\alpha$ signaling pathway. Cell communication and signaling : CCS, $17(1)$, 18. https://doi.org/10.1186/s12964-019-0331-9

Gedlicka, C., Hager, G., Weissenböck, M., Gedlicka, W., Knerer, B., Kornfehl, J., \& Formanek, M. (2006). 1,25(OH)2Vitamin D3 induces elevated expression of the cell cycle inhibitor p18 in a squamous cell carcinoma cell line of the head and neck. Journal of oral pathology \& medicine: official publication of the International Association of Oral Pathologists and the American Academy of Oral Pathology,35(8), 472-478. https://doi.org/10.1111/j.1600-0714.2006.00407.x

Gümüş, P., Öztürk, V. Ö., Bozkurt, E., \& Emingil, G. (2016). Evaluation of the gingival inflammation in pregnancy and postpartum via 25-hydroxy-vitamin D3, prostaglandin E2 and TNF- $\alpha$ levels in saliva. Archives of oral biology, 63, 1-6. https://doi.org/10.1016/j.archoralbio.2015.11.018

Hamidieh, A. A., Sherafatmand, M., Mansouri, A., Hadjibabaie, M., Ashouri, A., Jahangard-Rafsanjani, Z., Gholami, K., Javadi, M. R., Ghavamzadeh, A., \& Radfar, M. (2016). Calcitriol for Oral Mucositis Prevention in Patients With Fanconi Anemia Undergoing Hematopoietic SCT: A Double-Blind, Randomized, Placebo-Controlled Trial. American journal of therapeutics, 23(6), e1700-e1708. https://doi.org/10.1097/MJT.0000000000000269

Han, J., Cheng, C., Zhu, Z., Lin, M., Zhang, D. X., Wang, Z. M., \& Wang, S. (2019). Vitamin D reduces the serum levels of inflammatory cytokines in rat models of periodontitis and chronic obstructive pulmonary disease. Journal of oral science, 61(1), 53-60. https://doi.org/10.2334/josnusd.17-0357

Hartles, R. L., \& Shapiro, I. M. (1966). Changes in the rat incisor teeth in response to dietary deficiencies of calcium or phosphorus in the presence and absence of added vitamin D. Archives of oral biology, 11(1), 21-29. 
Hiremath, V. P., Rao, C. B., Naik, V., \& Prasad, K. V. (2013). Anti-inflammatory effect of vitamin D on gingivitis: a dose-response randomised control trial. Oral health \& preventive dentistry, 11(1), 61-69. https://doi.org/10.3290/j.ohpd.a29377

Hokugo, A., Christensen, R., Chung, E. M., Sung, E. C., Felsenfeld, A. L., Sayre, J. W., Garrett, N., Adams, J. S., \& Nishimura, I. (2010). Increased prevalence of bisphosphonate-related osteonecrosis of the jaw with vitamin D deficiency in rats. Journal of bone and mineral research : the official journal of the American Society for Bone and Mineral Research, 25(6), 1337-1349. https://doi.org/10.1002/jbmr.23

Hosokawa, Y., Hosokawa, I., Shindo, S., Ozaki, K., \& Matsuo, T. (2015). Calcitriol Suppressed Inflammatory Reactions in IL-1 $\beta-$ Stimulated Human Periodontal Ligament Cells. Inflammation, 38(6), 2252-2258. https://doi.org/10.1007/s10753-015-0209-y

Huang, Z., Zhang, Y., Li, H., Zhou, Y., Zhang, Q., Chen, R., Jin, T., Hu, K., Li, S., Wang, Y., Chen, W., \& Huang, Z. (2019). Vitamin D promotes the cisplatin sensitivity of oral squamous cell carcinoma by inhibiting LCN2-modulated NF-אB pathway activation through RPS3. Cell death \& disease, 10(12), 936. https://doi.org/10.1038/s41419-019-2177-x

Jabbar, S., Drury, J., Fordham, J., Datta, H. K., Francis, R. M., \& Tuck, S. P. (2011). Plasma vitamin D and cytokines in periodontal disease and postmenopausal osteoporosis. Journal of periodontal research, 46(1), 97-104. https://doi.org/10.1111/j.1600-0765.2010.01317.x

Jagur, O., Kull, M., Leibur, E., Kallikorm, R., Loorits, D., Lember, M., \& Voog-Oras, U. (2011). Relationship between radiographic changes in the temporomandibular joint and bone mineral density: a population based study. Stomatologija, 13(2), 42-48.

Ketharanathan, V., Torgersen, G. R., Petrovski, B. É., \& Preus, H. R. (2019). Radiographic alveolar bone level and levels of serum 25-OH-Vitamin D 3 in ethnic Norwegian and Tamil periodontitis patients and their periodontally healthy controls. BMC oral health, 19(1), 83. https://doi.org/10.1186/s12903-019$0769-6$

Kilinç, A., Tepecik, T., Dayi, E., \& Gündoğdu, B. (2017). Ossifying Fibroma Involving Three Quadrants of the Jaws in a Patient With Vitamin D Deficiency. The Journal of craniofacial surgery, 28(1), 296-297. https://doi.org/10.1097/SCS.0000000000003256

Krall, E. A., Wehler, C., Garcia, R. I., Harris, S. S., \& Dawson-Hughes, B. (2001). Calcium and vitamin D supplements reduce tooth loss in the elderly. The American journal of medicine, 111(6), 452-456.

Kribbs P. J. (1992). Two-year changes in mandibular bone mass in an osteoporotic population. The Journal of prosthetic dentistry, 67(5), 653-655. https://doi.org/10.1016/0022-3913(92)90164-6

Kühnisch, J., Thiering, E., Kratzsch, J., Heinrich-Weltzien, R., Hickel, R., Heinrich, J., GINIplus study group, \& LISAplus study group (2015). Elevated serum 25(OH)-vitamin D levels are negatively correlated with molar-incisor hypomineralization. Journal of dental research, 94(2), 381-387. https://doi.org/10.1177/0022034514561657

Li, H., Wang, Q., Xiao, Y., Bao, C., \& Li, W. (2013). 25-Hydroxyvitamin D(3)-loaded PLA microspheres: in vitro characterization and application in diabetic periodontitis models. AAPS PharmSciTech, 14(2), 880-889. https://doi.org/10.1208/s12249-013-9978-5

Li, H., Xie, H., Fu, M., Li, W., Guo, B., Ding, Y., \& Wang, Q. (2013). 25-hydroxyvitamin D3 ameliorates periodontitis by modulating the expression of inflammation-associated factors in diabetic mice. Steroids, 78(2), 115-120. https://doi.org/10.1016/j.steroids.2012.10.015

Li, H., Li, B., Wang, Q., Xiao, Y., Chen, X. M., \& Li, W. (2014). Attenuation of inflammatory response by 25- hydroxyvitamin D3-loaded polylactic acid microspheres in treatment of periodontitis in diabetic rats. The Chinese journal of dental research: the official journal of the Scientific Section of the Chinese Stomatological Association (CSA), 17(2), 91-98.

Li, H., Zhong, X., Li, W., \& Wang, Q. (2019). Effects of 1,25-dihydroxyvitamin D3 on experimental periodontitis and AhR/NF- $\kappa$ B/NLRP3 inflammasome pathway in a mouse model. Journal of applied oral science: revista FOB, 27, e20180713. https://doi.org/10.1590/1678-7757-2018-0713

Liberati, A., Altman, D. G., Tetzlaff, J., Mulrow, C., Gøtzsche, P. C., Ioannidis, J. P., ... \& Moher, D. (2009). The PRISMA statement for reporting systematic reviews and meta-analyses of studies that evaluate health care interventions: explanation and elaboration. Journal of clinical epidemiology, 62(10), e1-e34. Liu, K., Meng, H., Tang, X., Xu, L., Zhang, L., Chen, Z., \& Lu, R. (2009). Elevated plasma calcifediol is associated with aggressive periodontitis. Journal of periodontology, 80(7), 1114-1120.

Liu, K., Meng, H., Lu, R., Xu, L., Zhang, L., Chen, Z., Shi, D., Feng, X., \& Tang, X. (2010). Initial periodontal therapy reduced systemic and local 25hydroxy vitamin $\mathrm{D}(3)$ and interleukin-1beta in patients with aggressive periodontitis. Journal of periodontology, 81(2), 260-266. https://doi.org/10.1902/jop.2009.090355

Maher, R., Aga, P., Johnson, N. W., Sankaranarayanan, R., \& Warnakulasuriya, S. (1997). Evaluation of multiple micronutrient supplementation in the management of oral submucous fibrosis in Karachi, Pakistan. Nutrition and cancer, 27(1), 41-47. https://doi.org/10.1080/01635589709514499

Małodobra-Mazur, M., Paduch, A., Lebioda, A., Konopacka, M., Rogoliński, J., Szymczyk, C., \& Dobosz, T. (2012). VDR gene single nucleotide polymorphisms and their association with risk of oral cavity carcinoma. Acta Biochimica Polonica, 59(4).

Menzel, L. P., Ruddick, W., Chowdhury, M. H., Brice, D. C., Clance, R., Porcelli, E., Ryan, L. K., Lee, J., Yilmaz, Ö., Kirkwood, K. L., McMahon, L., Tran, A., \& Diamond, G. (2019). Activation of vitamin D in the gingival epithelium and its role in gingival inflammation and alveolar bone loss. Journal of periodontal research, 54(4), 444-452. https://doi.org/10.1111/jre.12646

Montava, M., Garcia, S., Mancini, J., Jammes, Y., Courageot, J., Lavieille, J. P., \& Feron, F. (2015). Vitamin D3 potentiates myelination and recovery after facial nerve injury. European archives of oto-rhino-laryngology : official journal of the European Federation of Oto-Rhino-Laryngological Societies (EUFOS) : affiliated with the German Society for Oto-Rhino-Laryngology - Head and Neck Surgery, 272(10), 2815-2823. https://doi.org/10.1007/s00405-014-3305-y

Morr Verenzuela, C. S., Davis, M., Bruce, A. J., \& Torgerson, R. R. (2017). Burning mouth syndrome: results of screening tests for vitamin and mineral deficiencies, thyroid hormone, and glucose levels-experience at Mayo Clinic over a decade. International journal of dermatology, 56(9), 952-956. https://doi.org/10.1111/ijd.13634 
Müller, K., Oxholm, P., Sørensen, O. H., Thymann, M., Høier-Madsen, M., \& Bendtzen, K. (1990). Abnormal vitamin D3 metabolism in patients with primary Sjögren's syndrome. Annals of the rheumatic diseases, 49(9), 682-684. https://doi.org/10.1136/ard.49.9.682

Murayama, T., Iwatsubo, R., Akiyama, S., Amano, A., \& Morisaki, I. (2000). Familial hypophosphatemic vitamin D-resistant rickets: dental findings and histologic study of teeth. Oral Surgery, Oral Medicine, Oral Pathology, Oral Radiology, and Endodontology, 90(3), $310-316$.

Nasreen, S., Ramesh, D., Thriveni, R., Bayatnal, A., Chowdhury, R. M., Kattimani, S., \& Saba, R. (2019). Assessment of alveolar bone mass using radio morphometric indices in urban and rural postmenopausal women and their correlation with serum vitamin D3 level. Indian journal of dental research : official publication of Indian Society for Dental Research, 30(5), 722-730. https://doi.org/10.4103/ijdr.IJDR_369_18

Nakashyan, V., Tipton, D. A., Karydis, A., Livada, R., \& Stein, S. H. (2017). Effect of 1,25(OH) $)_{2} \mathrm{D}_{3}$ and $20(\mathrm{OH}) \mathrm{D}_{3}$ on interleukin-1 $\beta$-stimulated interleukin-6 and -8 production by human gingival fibroblasts. Journal of periodontal research, 52(5), 832-841. https://doi.org/10.1111/jre.12452

Penoni, D. C., Torres, S. R., Farias, M. L., Fernandes, T. M., Luiz, R. R., \& Leão, A. T. (2016). Association of osteoporosis and bone medication with the periodontal condition in elderly women. Osteoporosis international : a journal established as result of cooperation between the European Foundation for Osteoporosis and the National Osteoporosis Foundation of the USA, 27(5), 1887-1896. https://doi.org/10.1007/s00198-015-3437-y

Qin, X., Shao, L., Zhang, L., Ma, L., \& Xiong, S. (2019). Investigation of Interaction between Vitamin D Receptor Gene Polymorphisms and Environmental Factors in Early Childhood Caries in Chinese Children. BioMed research international, 2019, 4315839. https://doi.org/10.1155/2019/4315839

Rosli, S. N., Shintani, T., Toratani, S., Usui, E., \& Okamoto, T. (2014). 1 $\alpha, 25(\mathrm{OH})_{2} \mathrm{D}_{3}$ inhibits FGF-2 release from oral squamous cell carcinoma cells through down-regulation of HBp17/FGFBP-1. In vitro cellular \& developmental biology. Animal, 50(9), 802-806. https://doi.org/10.1007/s11626-014-9787-5

Schroth, R. J., Rabbani, R., Loewen, G., \& Moffatt, M. E. (2016). Vitamin D and dental caries in children. Journal of dental research, 95(2), $173-179$.

Shintani, T., Rosli, S., Takatsu, F., Choon, Y. F., Hayashido, Y., Toratani, S., Usui, E., \& Okamoto, T. (2016). Eldecalcitol (ED-71), an analog of 1 $\alpha, 25-$ dihydroxyvitamin D3 as a potential anti-cancer agent for oral squamous cell carcinomas. The Journal of steroid biochemistry and molecular biology, 164, 7984. https://doi.org/10.1016/j.jsbmb.2015.09.043

Shintani, T., Takatsu, F., Rosli, S., Usui, E., Hamada, A., Sumi, K., Hayashido, Y., Toratani, S., \& Okamoto, T. (2017). Eldecalcitol (ED-71), an analog of $1 \alpha, 25(\mathrm{OH})_{2} \mathrm{D}_{3}$, inhibits the growth of squamous cell carcinoma (SCC) cells in vitro and in vivo by down-regulating expression of heparin-binding protein 17/fibroblast growth factor-binding protein-1 (HBp17/FGFBP-1) and FGF-2. In vitro cellular \& developmental biology. Animal, 53(9), 810-817. https://doi.org/10.1007/s11626-017-0183-9

Spolidorio, L. C., Herrera, B. S., Coimbra, L. S., Spolidorio, D. M., Muscará, M. N., \& Rossa, C., Jr (2010). Intermittent therapy with 1,25 vitamin D and calcitonin prevents cyclosporin-induced alveolar bone loss in rats. Calcified tissue international, 87(3), 236-245. https://doi.org/10.1007/s00223-010-9380-1

Sundaram, K., Sambandam, Y., Tsuruga, E., Wagner, C. L., \& Reddy, S. V. (2014). 1 1 ,25-dihydroxyvitamin D3 modulates CYP2R1 gene expression in human oral squamous cell carcinoma tumor cells. Hormones \& cancer, 5(2), 90-97. https://doi.org/10.1007/s12672-014-0170-5

Suresh, K. V., Nilesh, K., Mounesh Kumar, C. D., Patil, M. R., \& Pramod, R. C. (2014). Brown tumour of posterior maxilla associated with polydactyly, syndactyly and cardiac anomalies: a unique case report. Journal of clinical and diagnostic research: JCDR, 8(8), ZD31.

Thakur M. (2019). Familial Vitamin D-dependent rickets Type 2A: A report of two cases with alopecia and oral manifestations. Journal of oral and maxillofacial pathology : JOMFP,23(Suppl 1), 130-133. https://doi.org/10.4103/jomfp.JOMFP_309_18

Torrungruang, K., Chantarangsu, S., Sura, T., \& Thienpramuk, L. (2020). Interplay between vitamin D receptor FokI polymorphism and smoking influences Porphyromonas gingivalis proportions in subgingival plaque. Journal of clinical periodontology, 47(8), 912-920. https://doi.org/10.1111/jcpe.13307

Vincent-Chong, V. K., DeJong, H., Attwood, K., Hershberger, P. A., \& Seshadri, M. (2019). Preclinical Prevention Trial of Calcitriol: Impact of Stage of Intervention and Duration of Treatment on Oral Carcinogenesis. Neoplasia (New York, N.Y.), 21(4), 376-388. https://doi.org/10.1016/j.neo.2019.02.002

Wang, Q., Zhang, W., Li, H., Aprecio, R., Wu, W., Lin, Y., \& Li, Y. (2013). Effects of 25-hydroxyvitamin D3 on cathelicidin production and antibacterial function of human oral keratinocytes. Cellular immunology, 283(1-2), 45-50. https://doi.org/10.1016/j.cellimm.2013.06.007

Wang, Q., Zhou, X., Jiang, J., Zhang, P., Xia, S., Ding, Y., \& Wang, Q. (2019). Relationship between serum 25-hydroxyvitamin D 3 levels and severity of chronic periodontitis in type 2 diabetic patients: A cross-sectional study. Journal of periodontal research, 54(6), 671-680. https://doi.org/10.1111/jre.12669

Xiao, T. T., Li, X., Feng, J. L., \& Li, Y. (2018). Combined effects of aspirin and vitamin D3 on two OSCC cell lines: a preliminary study. Biotechnology letters, 40(3), 551-559. https://doi.org/10.1007/s10529-018-2508-5

Yang, S. W., Tsai, C. Y., Pan, Y. C., Yeh, C. N., Pang, J. H., Takano, M., Kittaka, A., Juang, H. H., Chen, T. C., \& Chiang, K. C. (2016). MART-10, a newly synthesized vitamin D analog, represses metastatic potential of head and neck squamous carcinoma cells. Drug design, development and therapy, 10, 19952002. https://doi.org/10.2147/DDDT.S107256

Yanık, S., Aras, M. H., Erkılıç, S., Bozdağ, Z., Demir, T., \& Çetiner, S. (2016). Histopathological features of bisphosphonates related osteonecrosis of the jaw in rats with and without vitamin d supplementation. Archives of oral biology, 65, 59-65. https://doi.org/10.1016/j.archoralbio.2015.10.010

Yuan, F. N., Valiyaparambil, J., Woods, M. C., Tran, H., Pant, R., Adams, J. S., \& Mallya, S. M. (2014). Vitamin D signaling regulates oral keratinocyte proliferation in vitro and in vivo. International journal of oncology, 44(5), 1625-1633. https://doi.org/10.3892/ijo.2014.2338

Zhang, P., Zhang, W., Zhang, D., Wang, M., Aprecio, R., Ji, N., Mohamed, O., Li, Y., Ding, Y., \& Wang, Q. (2018). 25-Hydroxyvitamin D -enhanced PTPN2 positively regulates periodontal inflammation through the JAK/STAT pathway in human oral keratinocytes and a mouse model of type 2 diabetes mellitus. Journal of periodontal research, 53(3), 467-477. https://doi.org/10.1111/jre.12535

Zhang, X., Meng, H., Sun, X., Xu, L., Zhang, L., Shi, D., Feng, X., Lu, R., \& Chen, Z. (2013). Elevation of vitamin D-binding protein levels in the plasma of patients with generalized aggressive periodontitis. Journal of periodontal research, 48(1), 74-79. https://doi.org/10.1111/j.1600-0765.2012.01505.X 
Research, Society and Development, v. 10, n. 15, e481101523019, 2021

(CC BY 4.0) | ISSN 2525-3409 | DOI: http://dx.doi.org/10.33448/rsd-v10i15.23019

Zhao, B., Xu, N., Li, R., Yu, F., Zhang, F., Yang, F., Ge, X., Li, Y. C., \& Du, J. (2019). Vitamin D/VDR signaling suppresses microRNA-802-induced apoptosis of keratinocytes in oral lichen planus. FASEB journal : official publication of the Federation of American Societies for Experimental Biology, 33(1), 1042-1050. https://doi.org/10.1096/fj.201801020RRR

Zhou, X., Zhang, P., Wang, Q., Xia, S., Ji, N., Ding, Y., \& Wang, Q. (2018). 25-Hydroxyvitamin $\mathrm{D}_{3}$ Alleviates Experimental Periodontitis via Promoting Expression of Cathelicidin in Mice with Type 2 Diabetic Mellitus. Journal of nutritional science and vitaminology, 64(5), 307-315. https://doi.org/10.3177/jnsv.64.307 